\title{
High-Resolution Global Climate Simulations with the ECMWF Model in Project Athena: Experimental Design, Model Climate, and Seasonal Forecast Skill
}

\author{
T. JUNG \\ ECMWF, Reading, United Kingdom, and AWI, Bremerhaven, Germany \\ M. J. Miller, T. N. PAlmer, P. TOWers, AND N. Wedi \\ ECMWF, Reading, United Kingdom
D. Achuthavarier, J. M. Adams, E. L. Altshuler, B. A. Cash, J. L. Kinter III, L. MARX, AND C. STAN
COLA, Calverton, Maryland \\ K. I. HODGES \\ ESSC, Reading, United Kingdom
}

(Manuscript received 12 May 2011, in final form 12 October 2011)

\begin{abstract}
The sensitivity to the horizontal resolution of the climate, anthropogenic climate change, and seasonal predictive skill of the ECMWF model has been studied as part of Project Athena-an international collaboration formed to test the hypothesis that substantial progress in simulating and predicting climate can be achieved if mesoscale and subsynoptic atmospheric phenomena are more realistically represented in climate models.

In this study the experiments carried out with the ECMWF model (atmosphere only) are described in detail. Here, the focus is on the tropics and the Northern Hemisphere extratropics during boreal winter. The resolutions considered in Project Athena for the ECMWF model are T159 (126 km), T511 (39 km), T1279 $(16 \mathrm{~km})$, and T2047 $(10 \mathrm{~km})$. It was found that increasing horizontal resolution improves the tropical precipitation, the tropical atmospheric circulation, the frequency of occurrence of Euro-Atlantic blocking, and the representation of extratropical cyclones in large parts of the Northern Hemisphere extratropics. All of these improvements come from the increase in resolution from T159 to T511 with relatively small changes for further resolution increases to T1279 and T2047, although it should be noted that results from this very highest resolution are from a previously untested model version. Problems in simulating the Madden-Julian oscillation remain unchanged for all resolutions tested. There is some evidence that increasing horizontal resolution to T1279 leads to moderate increases in seasonal forecast skill during boreal winter in the tropics and Northern Hemisphere extratropics. Sensitivity experiments are discussed, which helps to foster a better understanding of some of the resolution dependence found for the ECMWF model in Project Athena.
\end{abstract}

\section{Introduction}

While it is now widely accepted that anthropogenic emissions are responsible for increasing global mean temperatures since the industrial revolution, considerable uncertainty remains when it comes to the detection and attribution of changes in regional climates and extreme

Corresponding author address: Dr. Thomas Jung, AWI, Bussestr. 24, Bremerhaven, Germany.

E-mail: thomas.jung@awi.de events. At the World Modeling Summit for Climate Prediction in June 2008, scientists declared that progress in these areas is hampered by a lack of appropriate models and computers; in fact, this led Shukla et al. (2009) to propose that accelerated progress in our understanding and prediction of climate change hinges on the availability of enhanced national climate research facilities and the establishment of dedicated multinational facilities.

In 2009 the National Science Foundation (NSF) realized that there was an opportunity to test the possible benefit that could be gained from dedicated supercomputing 
facilities and their use for climate research through international collaboration. The NSF provided climate scientists from four centers, namely the Center for OceanLand-Atmosphere Studies (COLA), the European Centre for Medium-Range Weather Forecasts (ECMWF), the University of Tokyo, and the Japan Agency for MarineEarth Science and Technology (JAMSTEC), dedicated access for a 6-month period starting on 1 October 2009 to Athena, a 166-teraflop Cray XT4 system located at the National Institute for Computational Sciences (NICS) in Tennessee, hence, the name Project Athena (Kinter et al. 2011, manuscript submitted to Bull. Amer. Meteor. Soc.). The availability of this dedicated computing resource permitted the running of climate integrations with atmospheric circulation models from ECMWF and JAMSTEC at unprecedentedly high horizontal resolutions, which made it possible to resolve the synoptic-scale flow well while explicitly incorporating many mesoscale atmospheric features.

The project partners decided to use the available computer resources to investigate the influence that increasing horizontal resolution has on

- larger-scale aspects of model climate;

- specific atmospheric phenomena, such as the MaddenJulian oscillation;

- the atmospheric response to anthropogenic forcing; and - the skill of seasonal forecasts.

While the sensitivity to the horizontal resolution of all these aspects has been extensively studied in the past (e.g., Williamson et al. 1995; Branković and Gregory 2001), to our knowledge none of the previous studies has covered as wide a range of resolutions as is considered here, that is, resolutions from about $100 \mathrm{~km}$, typically used in climate research and seasonal forecasting, down to $10 \mathrm{~km}$, typically used in high-resolution numerical weather prediction.

The aim of this study is twofold. First, the wealth of different experiments carried out with the atmospheric component of the ECMWF Integrated Forecasting System (IFS hereafter) in Project Athena will be described in some detail (section 2). Second, some aspects of the influence of increased horizontal resolution on the climate of the model, its ability to represent certain atmospheric phenomena (section 3), and the skill of seasonal forecasts (section 4) will be explored. Finally the results will be summarized and discussed (section 5).

\section{Methods}

\section{a. Experimental setup}

The IFS (detailed documentation is available at http:// www.ecmwf.int/research/ifsdocs/) solves the hydrostatic primitive equations using a two-time-level, semi-implicit
semi-Lagrangian discretization (Ritchie et al. 1995; Temperton et al. 2001). Using the spectral transform method, the computation of advection, the physical parameterizations, and in particular the nonlinear terms is conducted on the linear reduced Gaussian grid (Hortal and Simmons 1991), while horizontal derivatives and the Helmholtz problem associated with the semi-implicit time stepping are computed in spectral space. In the Athena project, four different horizontal resolutions have been used, named according to the cutoff wavenumber used in the spherical harmonics expansion: T159, T511, T1279, and T2047 corresponding to 320, 1024, 2560, and 4096 grid points along the equator, respectively. In the vertical, the IFS is discretized with 91 hybrid vertical levels (top full level at $0.01 \mathrm{hPa}$ ) using a finite-element scheme (Untch and Hortal 2004).

The coupling between the dynamics and physics and an overview of the individual parameterization schemes is given by Beljaars et al. (2004). The convection parameterization is based on a mass flux scheme described in Tiedtke (1989), details of the original prognostic cloud scheme are given in Tiedtke (1993), the boundary layer scheme is discussed by Beljaars (1995), the radiation package is described in Morcrette et al. (2008), and the land surface scheme is explained in Viterbo and Beljaars (2005) and Balsamo et al. (2009). In recent years the ECMWF parameterization schemes have undergone substantial changes. A description of these changes along with an analysis of their impact on the model's climate and predictive skill are given elsewhere (Bechtold et al. 2008; Jung et al. 2010a).

Most of the different parameterization schemes were left unchanged across all resolutions. For the convection scheme, however, the convective adjustment time has been made dependent on resolution. This resolution dependence is largest for relatively low resolutions (i.e., going from T159 to T511). Also, Brown (2004) shows that the parameterized orographic gravity wave drag is reduced with increased horizontal resolution.

All atmosphere-only integrations with the IFS were carried out with observed SST and sea ice fields. Atmospheric initial conditions and lower boundary fields are a combination of T159 data from the 40-yr ECMWF Re-Analysis (ERA-40, covering 1960-89) and T255 data from ERA-Interim (1990-2007) interpolated spatially to the resolution of the model and, if necessary, linearly in time to obtain daily varying fields. For the period 1960-81, SST and sea ice fields are based on monthly mean values produced by the Met Office (Rayner et al. 2003). The weekly National Oceanic and Atmospheric Administration/National Centers for Environmental Prediction (NOAA/NCEP) two-dimensional variational data assimilation (2DVAR) dataset (Reynolds et al. 2002) was 
TABLE 1. Details of the various experiments carried out with the ECMWF model in the Athena Project.

\begin{tabular}{lcccc}
\hline \hline & T159 & T511 & T1279 & T2047 \\
\hline Resolution (km) & 125 & 40 & 15 & 10 \\
Radiation grid & T63 & T159 & T511 & T639 \\
Time step (min) & 60 & 15 & 10 & 7.5 \\
13 months $^{\mathrm{a}}$ & $1960-2007$ & $1960-2007$ & $1960-2007$ & $1989-2007$ \\
3 months $^{\mathrm{b}}$ & $2001-2009$ & - & $2001-2009$ & $2001-2009$ \\
AMIP style $^{\mathrm{c}}$ & $1960-2007$ & - & $1960-2007$ & - \\
Time slice $^{\mathrm{d}}$ & $2070-2117$ & - & $2070-2117$ & - \\
Seasonal $^{\quad}$ & see Tab. 2 & see Tab. 2 & see Tab. 2 & - \\
\hline
\end{tabular}

${ }^{\text {a }}$ Forecasts started on 1 November.

${ }^{\mathrm{b}}$ Forecasts started on 21 May and covered June-August.

${ }^{\mathrm{c}}$ Forecast started on 1 November 1960.

${ }^{\mathrm{d}}$ Forecast started with SST-sea ice forcing representing 1 November 2070

${ }^{\text {e }}$ Lagged seasonal ensemble forecasts (see Table 2 for details).

used until 2001 (ERA-Interim uses ERA-40 data until 2001). Finally, from 2002 onward, daily SST and sea ice data from the operational ECMWF analysis were employed.

Unless mentioned otherwise, all T511, T1279, and T2047 results presented in this study are based on postprocessed data that have been truncated/interpolated to T159/N80. By doing so, it is possible to more directly compare the model results with ERA-40 reanalysis data and therefore focus on spatial scales that are (at least theoretically) constrained by the observations.

In the following subsections the different experiment types are described in more detail (see also Table 1).

\section{1) 13-MONTH INTEGRATIONS}

The most comprehensive experimentation with the IFS as part of the Athena Project comprises 13-month long integrations started on 1 November of each of the years 1960-2007 for T159, T511, and T1279. Corresponding runs for T2047 were carried out for the years 1989-2007. The first month of the integrations was discarded to allow the model to reach its own climatology (Jung 2005). These integrations were set up to understand how horizontal resolution affects the simulated climate (mean and variability) of the IFS during all four seasons.

\section{2) 3-MONTH SUMMER INTEGRATIONS}

To be able to directly compare the IFS results with those obtained from the Nonhydrostatic Icosahedral Atmospheric Model (NICAM), additional integrations were carried out at T159, T1279, and T2047 for summers during 2001-09 (forecasts started on 21 May). The results from these integrations will be discussed in other forthcoming publications.

\section{3) AMIP-STYLE INTEGRATIONS}

Continuous atmosphere-only integrations for the period 1960-2007 with the IFS forced with the observed history of SST and sea ice fields, similar to the ones carried out in the Atmospheric Model Intercomparison Project (AMIP; Gates 1992), were carried out at T159 and T1279 for two reasons. First, it was decided to study the impact of resolution on systematic model error in long multidecadal integrations compared to relatively short seasonal and annual integrations in order to identify possible slow model drifts. Second, the AMIP integrations serve as the control experiment (representing presentday climate) for the time-slice experiments.

\section{4) TIME-SLICE EXPERIMENTS}

Time-slice experiments with the IFS covering the period 2070-17 were carried out at T159 and T1279 in order to study the influence that significantly increased horizontal resolution has on the atmospheric response to an anthropogenic forcing. Both forecasts were started using atmospheric initial conditions from ERA-40 from 1 November 1970. In the time-slice experiment both SST and sea ice concentrations were modified by adding perturbations taken as the difference between the 206575 and 1965-1975 monthly climatologies from a simulation with the Community Climate System Model (CCSM; Collins et al. 2006). A more detailed description of the approach is given in Schneider et al. (2009). Monthly values were then linearly interpolated to daily values. The CCSM experiment was carried out at T85 $(1.4 \times$ 1.4) for the atmosphere and on an approximately $1^{\circ}$ grid for the ocean and sea ice. The atmospheric greenhouse gas concentrations follow the Intergovernmental Panel on Climate Change (IPCC) emissions scenario A1B until the year 2100; thereafter, concentrations were held constant at their 2100 values.

\section{5) SEASONAL HindCASTS}

To study the influence of horizontal resolution on seasonal predictive skill, seasonal hindcasts with the IFS for selected boreal winter (December-February) and summer (June-August) cases were carried out at T159, T511, and T1279 (see Table 2). For each of the cases a 10-member lagged ensemble was generated. For winter (summer) cases, this was achieved by starting hindcasts in 6-hourly intervals from 1200 UTC 1 November to 1800 UTC 3 November (0600 UTC19 May to 1200 UTC 21 May).

\section{6) AdDitional SENSITIVITY EXPERIMENTS}

An additional set of 13-month T159 experiments for the period 1980-2007 with the same time step as the 
TABLE 2. Description of seasonal forecast experiments.

\begin{tabular}{lcl}
\hline \hline Season & Year & \multicolumn{1}{c}{ Climate anomaly } \\
\hline DJF & $2005 / 06$ & Euro-Atlantic blocking \\
DJF & $1997 / 98$ & Largest El Niño \\
DJF & $1998 / 99$ & Largest La Niña \\
DJF & $1982 / 93$ & Large El Niño \\
DJF & $1988 / 89$ & Large La Niña \\
DJF & $1976 / 77$ & Extreme North American weather \\
JJA & 1988 & Record drought in North America \\
& & and India \\
JJA & 1993 & Record flooding in North America \\
JJA & 2003 & Record heat wave in Europe \\
JJA & 2005 & Record Atlantic hurricane season \\
JJA & 1997 & Early onset El Niño with teleconnections \\
JJA & 2004 & Active typhoon season in western Pacific \\
\hline
\end{tabular}

T511 simulations (i.e., $15 \mathrm{~min}$ ) was carried out (T159 $15 \mathrm{~min}$ hereafter) to assess the time-step dependence of the IFS for long integrations and distinguish from effects due to increasing spatial resolution. Time-step dependence in the IFS has three dominant sources-the individual physical parameterizations, the coupling of the physical parameterizations to the dynamics, and the frequency of invocation of the semi-Lagrangian interpolations at the departure point of the trajectory-leading to an increased implicit horizontal diffusion with a shorter time step at the same resolution (i.e., more interpolations). Increased horizontal resolution necessitates of course a decrease in time step for stability and numerical accuracy. However, the increased frequency of the interpolations is balanced by the relatively smaller physical size of the interpolation stencil.

Finally, a set of 5-month-long integrations started on 1 November of each of the years 1989-2007 was carried out at T511 but with the prescribed orography from the T159 model (T511 ${ }_{\mathrm{O} 159}$ hereafter). This additional experiment allows us to understand to what degree the improvements seen when going from T159 to T511 are due to a better representation of processes associated with the resolved orography.

\section{b. Extratropical cyclone tracking}

In this study, synoptic-scale extratropical cyclone characteristics are investigated by employing a featuretracking technique that has been used in numerous previous studies of extratropical cyclones (e.g., Hoskins and Hodges 2002; Bengtsson et al. 2006; Hodges et al. 2011). In this scheme, which has been developed by Hodges (1995, 1999), extratropical cyclones are identified as maxima or minima of 6-hourly fields of relative vorticity at $850 \mathrm{hPa}\left(\xi_{850}\right)$ and mean sea level pressure (MSLP), respectively, in the Northern Hemisphere. Before the identification, the large-scale background field is first removed for reasons described in Hoskins and Hodges (2002). Furthermore, $\xi_{850}$ is truncated to T42 and MSLP to T106, respectively, in order to reduce problems associated with noise and to focus on the synoptic-scale storms. This reduction in resolution allows the storms to be identified at a common spatial scale and hence when it comes to comparing intensity distributions, they are not biased by large numbers of small-scale systems as resolution increases. Spatial statistics are computed from the extratropical cyclone tracks using the spherical kernel approach of Hodges (1996). Here, track densities are differenced to highlight where differences in the distribution of extratropical cyclones occur; the significance of these differences is tested using a Monte Carlo approach described in Hodges (2008). Finally, for some applications the extratropical cyclone tracks will be referenced back to the full-resolution fields of $\xi_{850}$, MSLP, and $925-\mathrm{hPa}$ wind speed, as described in Bengtsson et al. (2009), to explore the impact of resolution on the intensities.

\section{c. Reanalysis data}

ERA-40 (Uppala et al. 2005) and ERA-Interim (Simmons et al. 2007) reanalysis data were used for two purposes. First, the respective reanalysis fields were used to initialize the forecasts (free-atmosphere and land surface fields). Second, unless mentioned otherwise, merged reanalysis fields (ERA hereafter) were used for verification by combining ERA-40 (1960-2001) with ERAInterim (2002-07) data.

\section{Model climate}

\section{a. Mean climate}

\section{1) AtMospheric CIRCULATION}

The mean systematic errors in geopotential height at $500 \mathrm{hPa}$ (Z500) during boreal winter (DecemberFebruary, DJF) for 13-month integrations with the T159 version of the IFS are shown in Fig. 1a. Generally, systematic Z500 errors in the extratropics are rather small, even at this relatively low horizontal resolution. This is consistent with results from the study by Jung et al. (2010a), which show that improvements in the ECMWF parameterization package during the last $5 \mathrm{yr}$ or so have led to substantial improvements in the simulation of the extratropical atmospheric circulation with the T159 version of the IFS.

Mean Z500 differences between T511 and T159 show that increasing resolution from T159 to T511 further reduces the remaining errors in most parts of the Northern and Southern Hemisphere extratropics (Fig. 1b). Further increasing horizontal resolution from T511 to T1279 and 

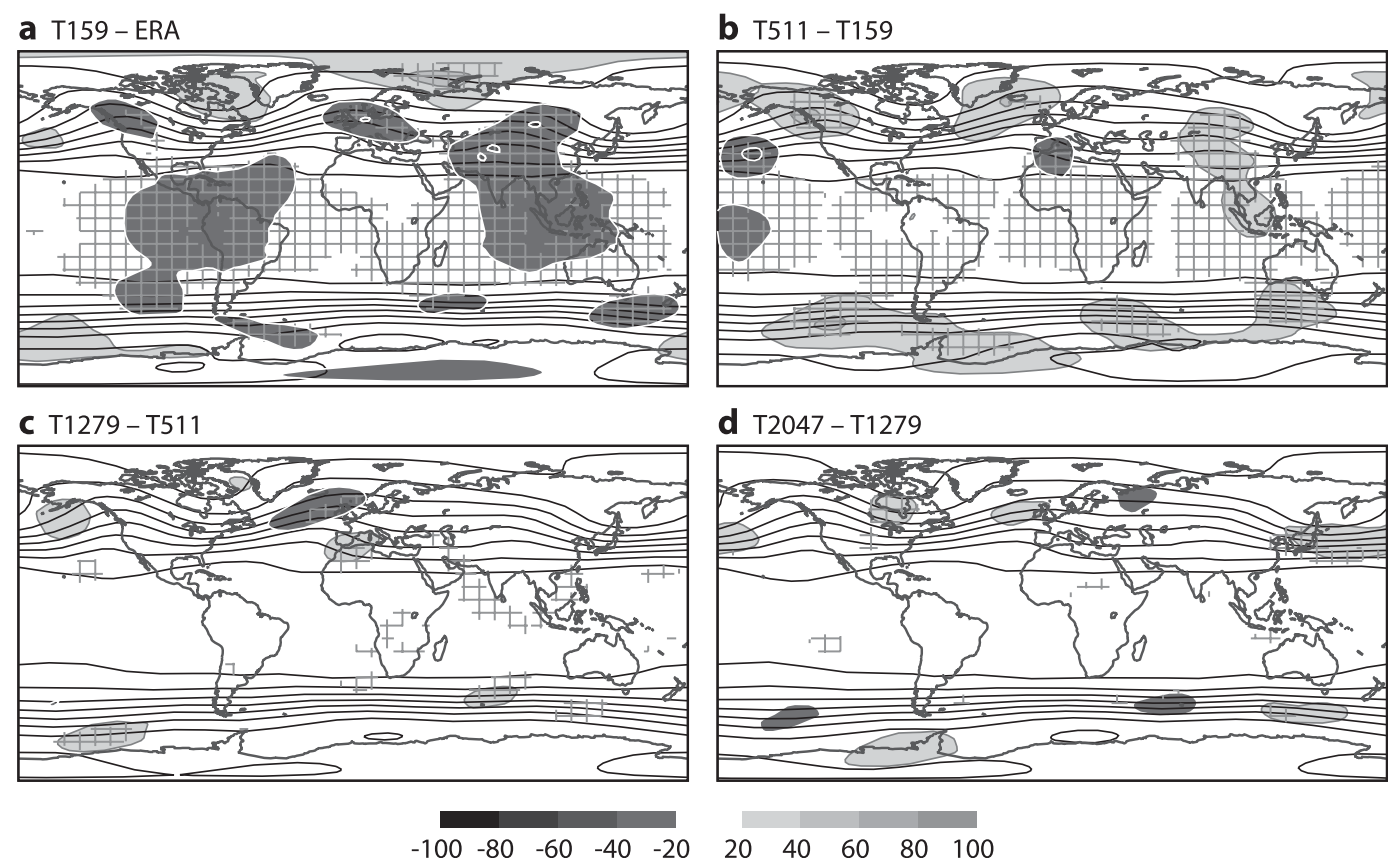

FIG. 1. Differences in average 500-hPa geopotential height fields (gray shading in $\mathrm{m}$ ) from 13-month integrations for winters (DJF) during 1989/90-2007/08: (a) T159-Reanalysis, (b) T511-T159, (c) T1279-T511, and (d) T2047T1279. Also shown are mean fields (contour interval is $50 \mathrm{~m}$ ) for (a) reanalysis data and (b)-(d) the respective lowerresolution model. Differences statistically significant at the $95 \%$ confidence level are hatched.

T2047, respectively, leads to relatively minor extratropical changes in the mean Z500 fields (Figs. 1c,d).

The mean systematic Z500 errors for the AMIP-type runs with the T159 version of the IFS are shown in Fig. $2 \mathrm{a}$ for the period 1962/63-2007/08. The similarity of the results to the 13-month-long integrations (Fig. 1a) is striking. This suggests that most of the systematic Z500 errors have fully developed within weeks to months (see also Jung 2005) and that any possible slow drift of the surface characteristics over land (SST and sea ice are prescribed) has little influence on the atmospheric circulation in the extratropics. The same conclusion holds for the T1279 version of the model (Fig. 2b).

One of the most important changes in the parameterization package of the IFS in recent years was the modification of the convection scheme, which was introduced into the IFS in 2008 (Bechtold et al. 2008). In general, the new convection scheme led to major improvements (Bechtold et al. 2008; Jung et al. 2010a). However, the introduction of the new scheme also had detrimental effects, including the development of a near-surface easterly wind bias in the central and western tropical Pacific with implications for the quality of seasonal forecasts of the El Niño-Southern Oscillation phenomenon with the coupled atmosphere-ocean model from ECMWF (not shown). This error can be clearly seen in mean $850-\mathrm{hPa}$ wind fields obtained from the 13-month integrations with the T159 version of the IFS (Fig. 3a). Increasing resolution from T159 to T511 reduces the easterly wind biases substantially (Fig. 3b). Increasing resolution further to T1279 and T2047 has a rather small impact on tropical near-surface winds (Figs. 3c,d).

Increasing resolution from T159 to T511 is not only beneficial for near-surface winds; in fact, the simulation of the whole meridional mean zonal circulation of the tropical troposphere is substantially improved when going from T159 to T511 (Figs. 4a,b). As for the near-surface winds, increasing resolution from T511 to T1279 and T2047, respectively, has rather little impact (Figs. 4c,d).

Interestingly, both the improvement in near-surface winds in the tropical Pacific and the meridional mean circulation in the tropics found when going from T159 to T511 can also be achieved if the coarser-resolution, T159 model is run with the same, shorter time step used by the T511 model (i.e., $15 \mathrm{~min}$ ). This suggests that the improvements seen in near-surface tropical winds when going from T159 to T511 are primarily due to the shorter time step required to attain stability rather than increased horizontal resolution.

\section{2) Precipitation}

Systematic errors of the T159 model in simulating precipitation during boreal winter are shown in Fig. 5a. The results for the model version used here are very similar 
a T159-ERA

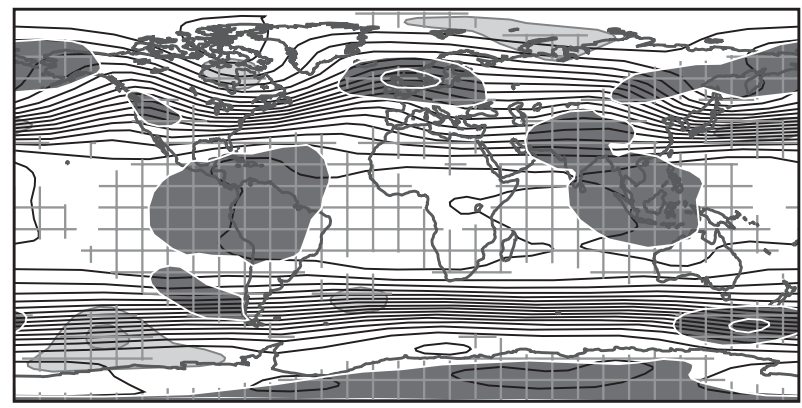

b T1279-ERA

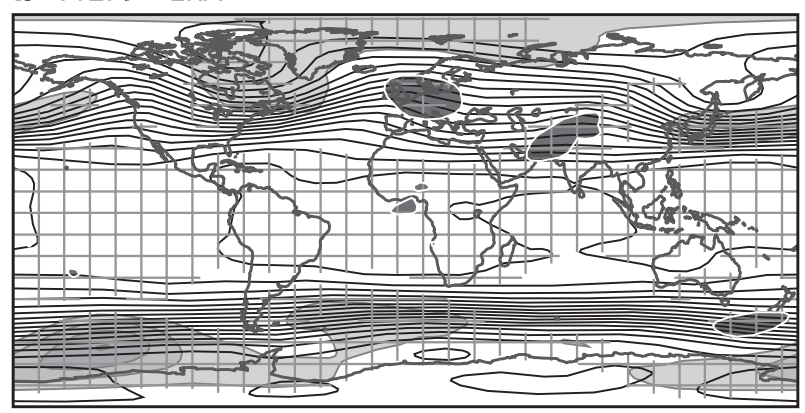

$\begin{array}{llllllllll}-100 & -80 & -60 & -40 & -20 & 20 & 40 & 60 & 80 & 100\end{array}$

FIG. 2. As in Fig. 1a, but for AMIP-style integrations at (a) T159 and

(b) T1279 for boreal winters during the period 1962/63-2006/07.

to other more recent model versions [see Jung et al. (2010a) for a more comprehensive discussion]. In the tropics the T159 model shows systematic precipitation errors of substantial size. This is especially true over the western tropical Indian Ocean. The T159 version of the model also produces too much precipitation over the Maritime Continent; the associated excess of diabatic heating may at least partly explain the existence of the near-surface easterly wind biases found in the tropical Pacific (Fig. 3a). Increasing horizontal resolution from T159 to T511 is beneficial in most parts of the tropics. Increasing horizontal resolution further to T1279 and T2047 has little impact except for over the Maritime Continent, where precipitation decreases further with increasing resolution.

It is interesting to further study the relative impact of increased horizontal resolution on parameterized, convective, and "resolved" large-scale precipitation separately. One could expect that convective (large scale) precipitation reduces (increases) with increasing horizontal resolution. However, this is not what comes out of the Athena experiments (Table 3). In the tropics, for example, it is found for both 13-month and AMIP-style integrations that the amount of convective precipitation hardly changes (reduction of about $2 \%$ ) compared to the amount of large-scale precipitation (increase of about $30 \%)$. Generally, in the extratropics the picture is very similar with the exception that the relative increase in large-scale precipitation is less pronounced than that in the tropics.

\section{b. Atmospheric phenomena}

\section{1) EXTRATROPICAL CYCLONES}

The numbers of extratropical cyclones in the Northern Hemisphere during the period 1989/90-2007/08 are given in Table 4 for ERA-Interim and the various 13-month forecast experiments. Independent of the exact
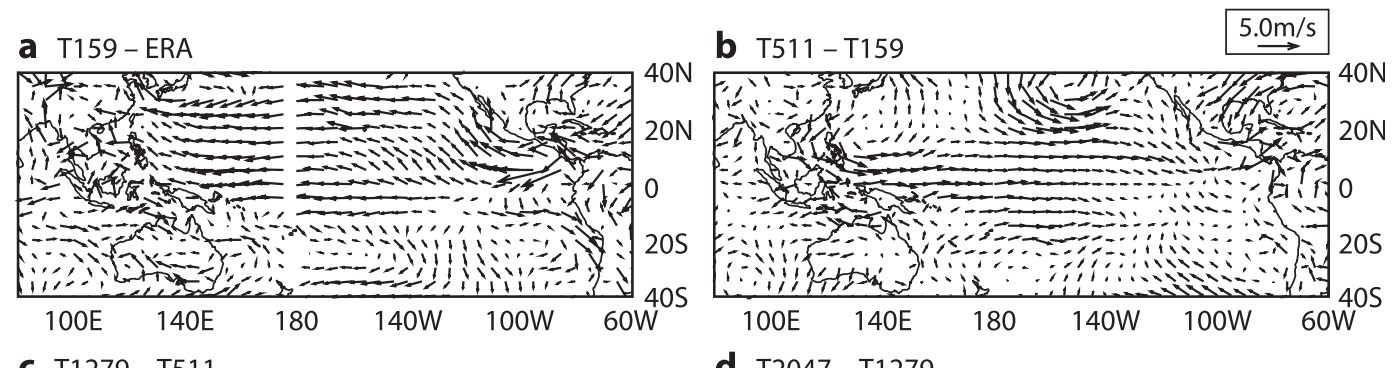

C $\mathrm{T} 1279-\mathrm{T} 511$

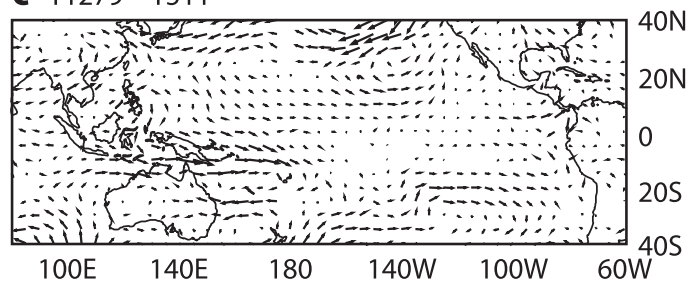

d $\mathrm{T} 2047-\mathrm{T} 1279$

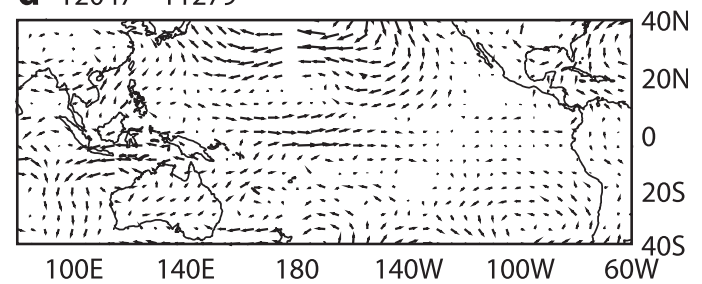

FIG. 3. Difference in average wind fields at $850 \mathrm{hPa}$ from 13-month integrations for winters (DJF) during the period 1989/90-2007/08: (a) T159-ERA40, (b) T511-T159, (c) T1279-T511, and (d) T2047-T1279. A reference vector is given (in $\mathrm{m} \mathrm{s}^{-1}$ ). 

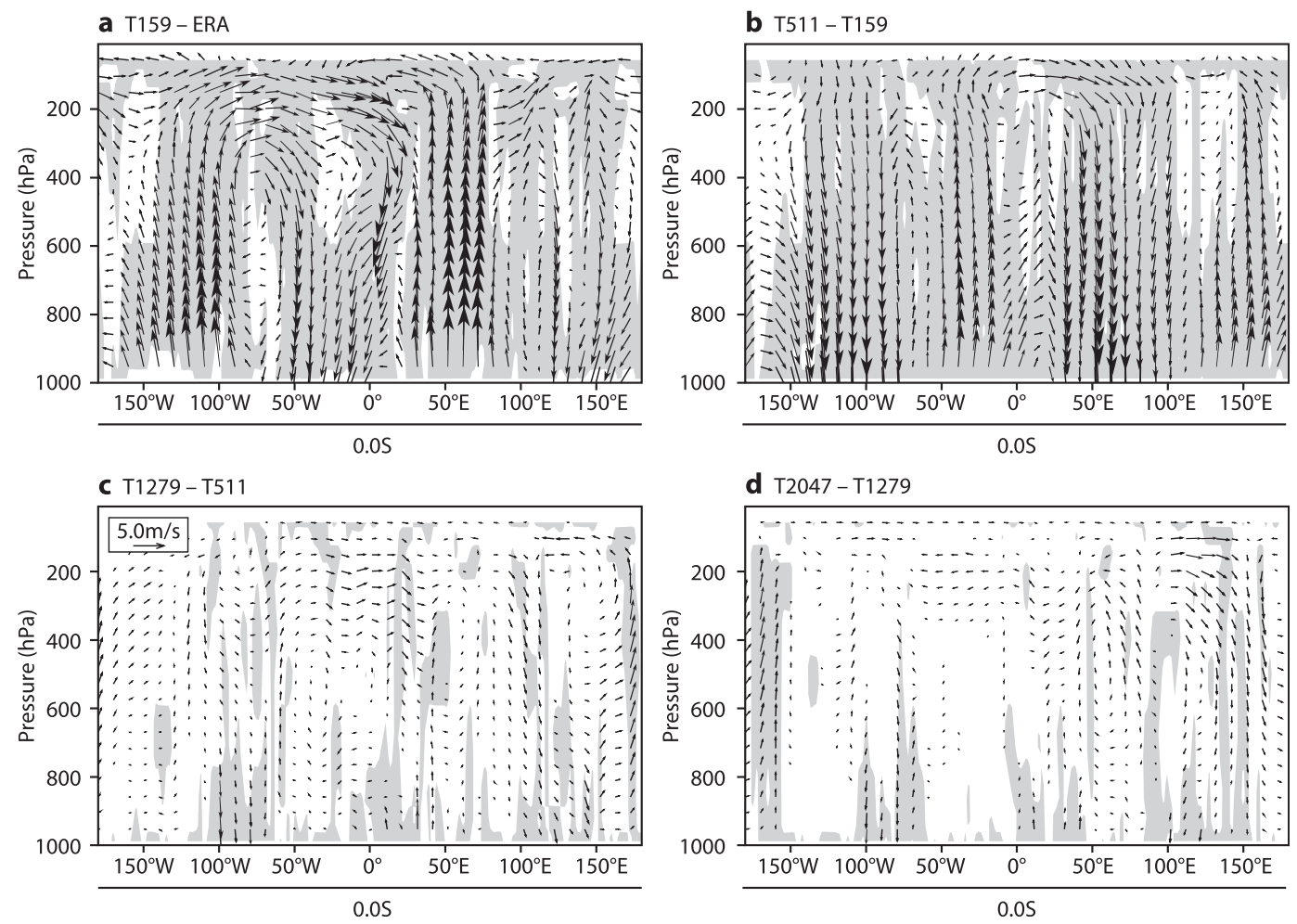

FIG. 4. Difference in average Walker circulation $\left(\mathrm{m} \mathrm{s}^{-1}\right)$ from 13 -month integrations for winters (DJF) during the period 1989/90-2007/08: (a) T159-ERA40, (b) T511-T159, (c) T1279-T511, and (d) T2047-T1279. Results are based on meridionally averaging $\left(20^{\circ} \mathrm{S}-20^{\circ} \mathrm{N}\right)$ zonal and vertical wind components. Differences statistically significant at the $95 \%$ confidence level are shaded. A reference vector is given.

selection criterion and the parameter (vorticity versus MSLP) used, the following picture emerges. The T159 model underestimates the number of Northern Hemisphere cyclones both during boreal winter (about 6.5\%) and summer (about 10\%). Increasing resolution to T511 and beyond leads to a very realistic and statistically significant (at the 5\% confidence level; not shown) increase in the number of extratropical cyclones over the Northern Hemisphere. Reducing the time step of the T159 model leads to a statistically significant (at the 5\% confidence level) reduction in the number of cyclones over the Northern Hemisphere extratropics. Finally, the results for the T511 model run with T159 orography show that improved cyclone statistics are not a results of a better explicit representation of the Earth's topography [see, e.g., Jung and Rhines (2007) for a related discussion of this issue]. It is also apparent for all experiments that more systems are identified for vorticity than for MSLP even though the vorticity is truncated to T42 and the MSLP at a much higher resolution.

Figure 6 shows systematic errors relative to ERAInterim fields in the Northern Hemisphere track densities of vorticity at $850 \mathrm{hPa}$ for the different experiments. Note that the track density is computed by using a single point from each track that is closest to the "grid point" for which track densities are estimated. In this way slowmoving systems cannot have a large contribution to the density in a small region, which can occur if all the track points were used. For the T159 model, track densities are underestimated almost everywhere in the middle and high latitudes of the Northern Hemisphere. This underestimation, although less pronounced, is broadly consistent with the results found in an earlier study using older IFS versions and MSLP to identify the cyclones (Jung et al. 2006). In the subtropics of the Northern Hemisphere the T159 model tends to overestimate track densities. The overestimation is especially pronounced over Europe and the Mediterranean. Interestingly, the earlier model cycles used by Jung et al. (2006) showed an underestimation of Mediterranean cyclones at T159. This suggests that recent changes in the physical parameterization package of the IFS (Jung et al. 2010a) had a substantial impact on cyclogenesis in the lee of the Alps, a finding that merits further investigation.

Increasing horizontal resolution to T511 and higher generally leads to more realistic cyclone track densities, especially in middle and high latitudes (Figs. 6b-d). However, there are regions in which systematic track density 


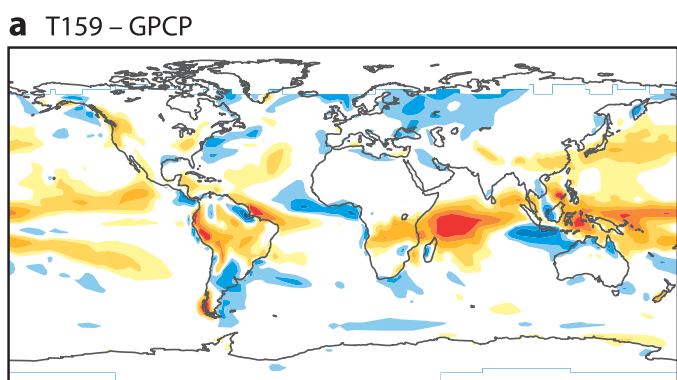

b $\mathrm{T} 511-\mathrm{T} 159$
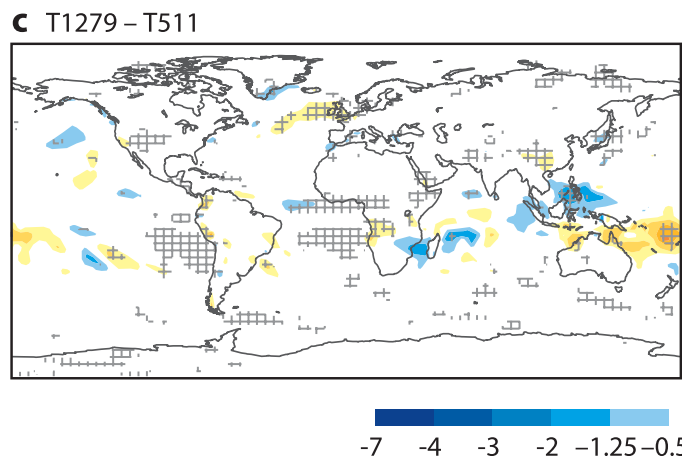

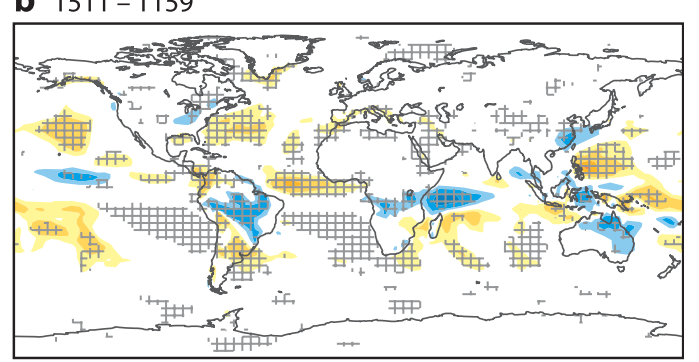

d $\mathrm{T} 2047-\mathrm{T} 1279$
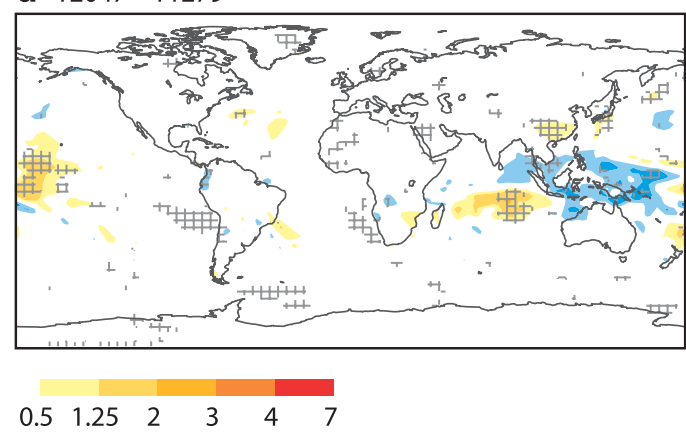

FIG. 5. As in Fig. 1, but for total precipitation $\left(\mathrm{mm} \mathrm{day}^{-1}\right)$. Observational data are based on the Global Precipitation Climatology Project (GPCP; Adler et al. 2003).

errors are hardly altered by increased horizontal resolution. The underestimation of cyclone track densities in the storm track entrance regions over the western boundary currents, for example, hardly improves with increasing horizontal resolution. Jung et al. (2006) hypothesized that this is a result of the smoothness of the underlying SST fields; in light of the results obtained in the present study and the study by Woollings et al. (2010), it seems important to test this conjecture in a follow-on study. Interestingly, the overestimation of lee cyclogenesis also shows little, if any, improvement with increased horizontal resolution (not shown).

Reducing the time step of the T159 model to $15 \mathrm{~min}$ deteriorates the extratropical cyclone track densities in

TABLE 3. Mean convective/large-scale precipitation $\left(\mathrm{mm} \mathrm{day}^{-1}\right)$ integrated over different domains. Results are based on boreal winters (DJF) of the period 1989-2007 (1989-2006) for 13-month (AMIP style) integrations.

\begin{tabular}{lcccc}
\hline \hline Region & T159 & T511 & T1279 & T2047 \\
\hline \multicolumn{5}{c}{13 -month integrations } \\
$15^{\circ} \mathrm{S}-15^{\circ} \mathrm{N}$ & $3.54 / 1.03$ & $3.57 / 1.13$ & $3.52 / 1.23$ & $3.46 / 1.29$ \\
$20^{\circ}-90^{\circ} \mathrm{N}$ & $1.01 / 1.10$ & $1.06 / 1.18$ & $1.05 / 1.20$ & $1.05 / 1.23$ \\
$20^{\circ}-90^{\circ} \mathrm{S}$ & $1.21 / 1.10$ & $1.18 / 1.29$ & $1.17 / 1.35$ & $1.17 / 1.39$ \\
\multicolumn{5}{c}{ AMIP-style integrations } \\
$15^{\circ} \mathrm{S}-15^{\circ} \mathrm{N}$ & $3.56 / 1.01$ & - & $3.55 / 1.24$ & - \\
$20^{\circ}-90^{\circ} \mathrm{N}$ & $1.04 / 1.10$ & - & $1.08 / 1.20$ & - \\
$20^{\circ}-90^{\circ} \mathrm{S}$ & $1.20 / 1.11$ & - & $1.20 / 1.37$ & - \\
\hline
\end{tabular}

large parts of the Northern Hemisphere (Fig. 6e). Furthermore, the fact that extratropical cyclone track densities in the T511 run with explicit T159 orography are comparable to the T511 run with T511 orography suggests that the improvement seen when going from T159

TABLE 4. Average number of extratropical cyclones per month for the Northern Hemisphere extratropics $\left(30^{\circ}-90^{\circ} \mathrm{N}\right)$ and the period 1989/90-2007/08. Results are shown for relative vorticity at $850 \mathrm{hPa}\left(\xi_{850}\right)$ truncated to T42 and SLP truncated to T106, as well as three different selection criteria: minimum lifetime of 2 days and minimum migration distance of $1000 \mathrm{~km}$ (Crit-1), minimum lifetime of 2 days (Crit-2), and minimum lifetime of 1 day (Crit-3).

\begin{tabular}{|c|c|c|c|c|c|c|}
\hline \multirow[b]{2}{*}{ Resolution } & \multicolumn{3}{|c|}{$\xi_{850}$} & \multicolumn{3}{|c|}{ SLP } \\
\hline & Crit-1 & Crit-2 & Crit-3 & Crit-1 & Crit-2 & Crit-3 \\
\hline \multicolumn{7}{|c|}{ December-February } \\
\hline ERA-Interim & 130.8 & 167.3 & 282.3 & 80.8 & 111.8 & 198.8 \\
\hline $\mathrm{T} 159$ & 122.2 & 159.2 & 259.2 & 87.1 & 128.2 & 248.9 \\
\hline T511 & 130.7 & 165.3 & 271.9 & 95.74 & 139.6 & 289.0 \\
\hline T1279 & 128.4 & 163.4 & 270.2 & 93.0 & 140.8 & 291.9 \\
\hline T2047 & 130.5 & 164.6 & 270.8 & 91.9 & 137.7 & 287.4 \\
\hline $\mathrm{T} 159_{15 \min }$ & 119.3 & 157.4 & 253.9 & 83.1 & 126.4 & 243.7 \\
\hline T511 & 131.3 & 165.5 & 272.9 & 96.5 & 141.5 & 294.4 \\
\hline \multicolumn{7}{|c|}{ Jun-Aug } \\
\hline ERA-Interim & 100.0 & 152.0 & 234.1 & 67.9 & 129.3 & 220.7 \\
\hline $\mathrm{T} 159$ & 89.5 & 142.6 & 209.8 & 72.8 & 165.8 & 299.0 \\
\hline T511 & 97.1 & 148.6 & 223.2 & 78.9 & 175.6 & 331.9 \\
\hline T1279 & 98.6 & 151.1 & 225.8 & 80.0 & 176.2 & 333.7 \\
\hline T2047 & 99.7 & 150.1 & 223.1 & 79.3 & 175.4 & 333.5 \\
\hline $\mathrm{T} 159_{15 \min }$ & 86.3 & 140.9 & 207.9 & 69.7 & 162.2 & 293.0 \\
\hline
\end{tabular}


a T159-ERA

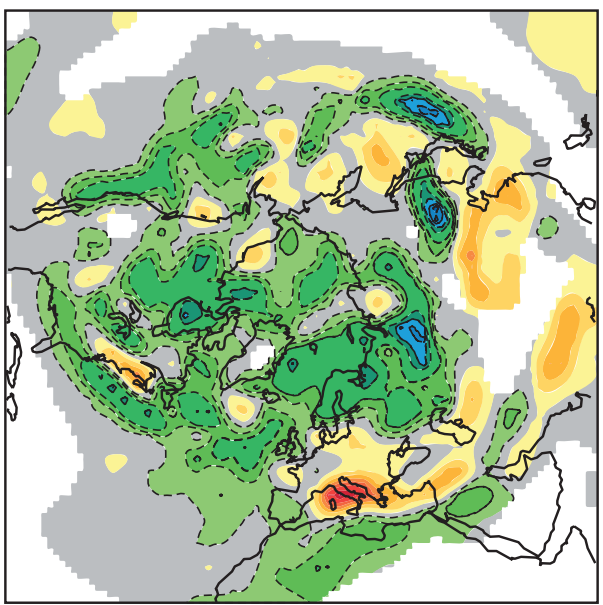

c T1279-ERA

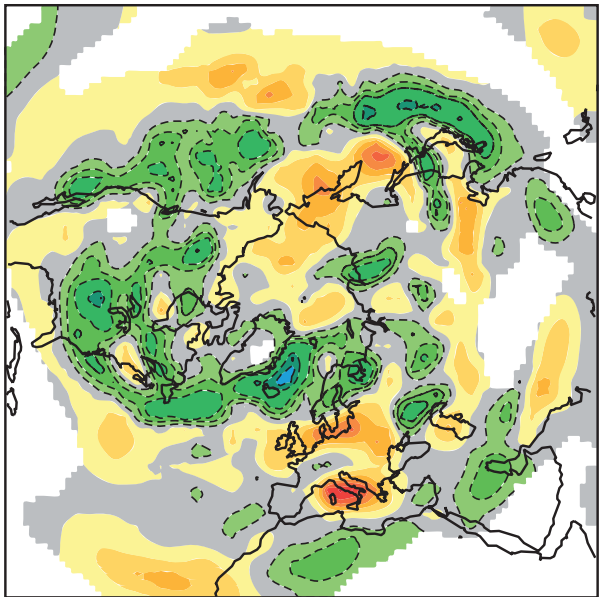

e $T 159_{15 \mathrm{~min}}$ - ERA

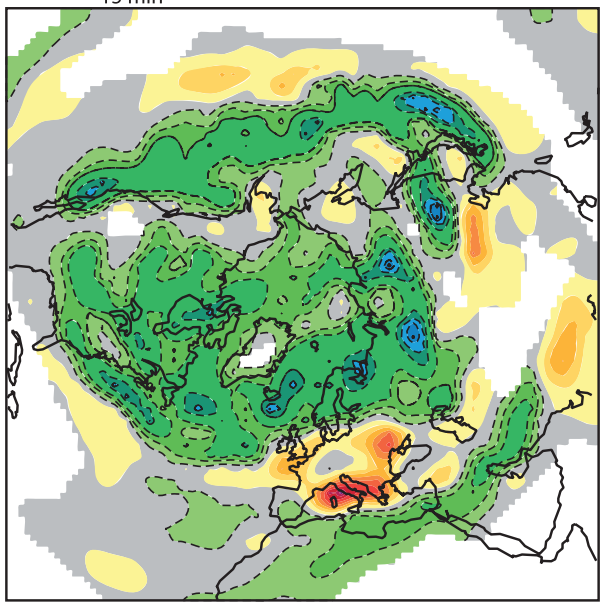

b T511 - ERA

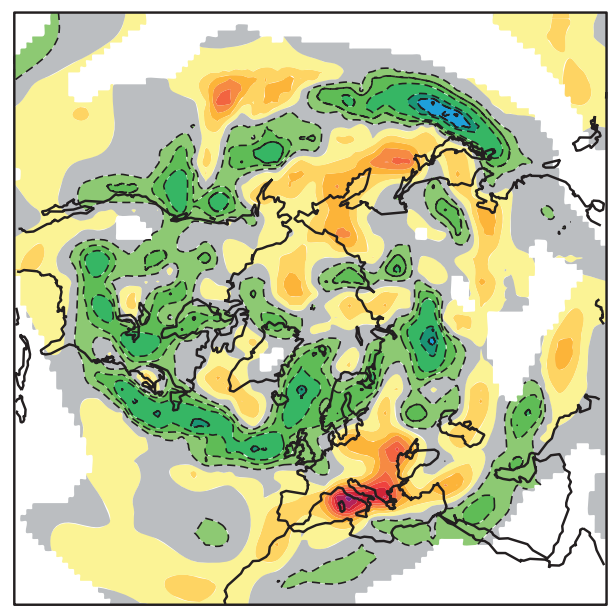

d T2047 - ERA

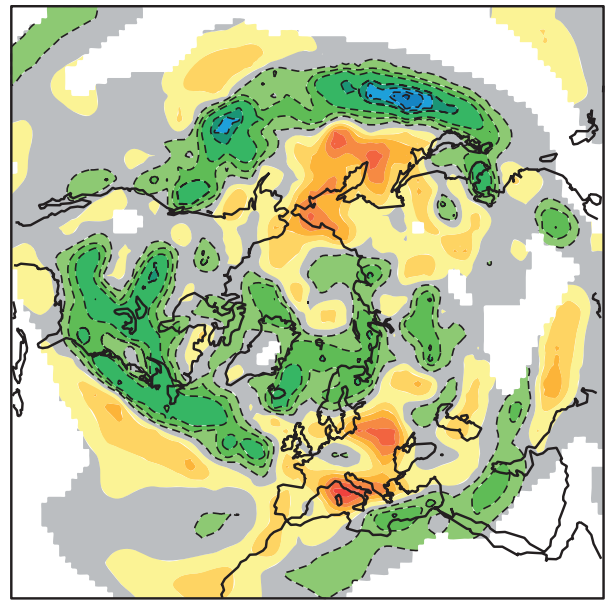

f $T 511_{0159}$ - ERA

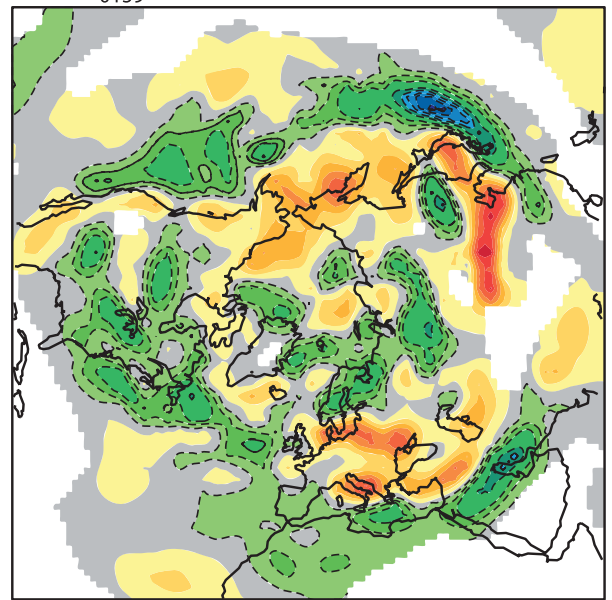

$\begin{array}{llllllllllllllllll}-5.9 & -5.2 & -4.6 & -3.9 & -3.2 & -2.5 & -1.8 & -1 & -0.3 & 0.4 & 1 & 1.8 & 2.5 & 3.2 & 3.9 & 4.6 & 5.2 & 5.9\end{array}$

FIG. 6. Differences in track density of vorticity maxima at $850 \mathrm{hPa}$ from 13-month integrations for winters (DJF) during the period 1989/90-2007/08: (a) T159-ERA-Interim, (b) T511-ERA-Interim, (c) T1279-ERA-Interim, (d) T2047-ERA-Interim, (e) T159 ${ }_{15 \mathrm{~min}}$-ERA-Interim, and (f) T511 ${ }_{\mathrm{O} 159^{-}}$-ERAInterim. Results are based on mobile systems $(\geq 1000 \mathrm{~km})$ only with a minimum lifetime of 2 days. 
to T511 has to do with a better representation of subsynoptic features rather than indirectly through the topographic influence on the large-scale circulation and hence the storm tracks (see also next section).

Given the increasing interest in extreme events, it is useful to consider the distribution of extratropical cyclone intensities in more detail. Figure 7 shows the frequency of occurrence of extratropical cyclone maximum intensities expressed in terms of SLP, vorticity at $850 \mathrm{hPa}$, and wind speed at $925 \mathrm{hPa}$ for the winters during the period 1989/90-2007/08. The intensities were obtained by referencing the T159 (solid lines) and native T511 (dashed lines) fields. The first thing to notice is that differences among curves are largest for vorticity, followed by wind speed and MSLP. This reflects the fact that vorticity is the smallest-scale field (followed by wind speed) for which resolution effects should be most important. For all three parameters the T159 model results stand out in the sense that the frequency of occurrence of intense and extreme extratropical cyclones is underestimated compared to ERA-Interim. The largest change in extratropical cyclone intensities is found when going from T159 to T511. The T511, T1279, and T2047 data, which have been truncated to T159 (solid curves), show very similar distributions for extratropical cyclone intensities (for MSLP, vorticity, and wind). The distribution for ERA-Interim lies somewhere between the T159 and truncated T511, T1279, and T2047 model fields. In light of the discussion of this section, it seems plausible to assume that ERA-Interim also underestimates the occurrence of extreme extratropical cyclones due to the use of a relatively coarse-resolution model (T255).

Especially for vorticity, large differences in the distribution of extratropical cyclone intensities show up when results from native (T511 $1_{\mathrm{FULL}}$ ) and truncated T511 fields are compared (red curves in Fig. 7b). These differences are even more pronounced for T1279 and T2047 (not shown) without any obvious convergence. Focusing solely on the diagnostics obtained from truncated fields clearly underestimates the role of horizontal resolution for small-scale fields such as vorticity. In fact, at very high resolutions, vorticity may not really be suitable as a general measure of storm intensity due to its small-scale nature; especially if a single point is used, an area average may be better. For winds at $925 \mathrm{hPa}$ using native rather than truncated T1279 and T2047 data "shifts" the tails of the probability density function by about $3 \mathrm{~m} \mathrm{~s}^{-1}$ toward higher values (not shown); no discernible effect of using high-resolution rather than truncated data is found for MSLP data (for T511 and higher).

Finally, a comparison of the T511 with the T511 $1_{\mathrm{O} 159}$ experiment at native resolution (subscript FULL) shows that the increased occurrence of intense and extreme
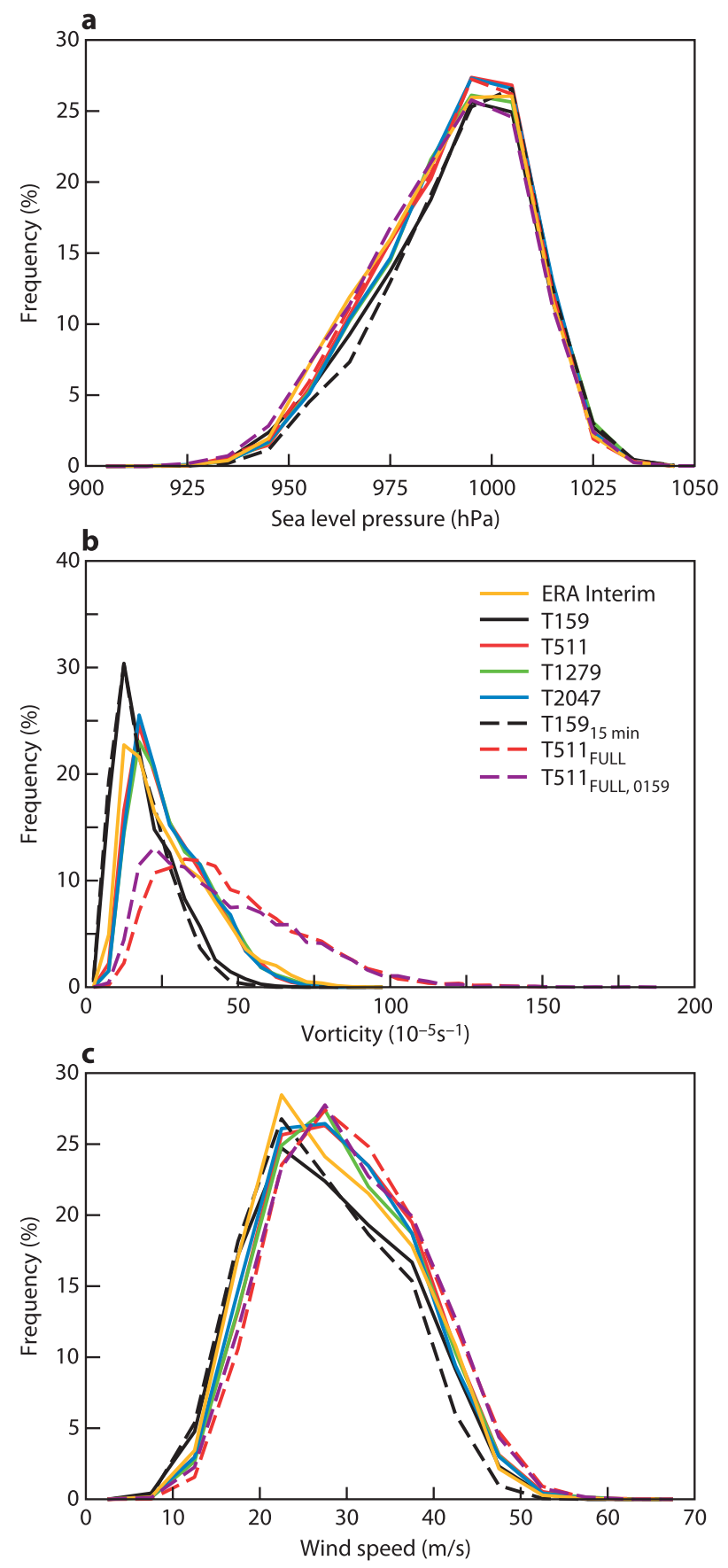

FIG. 7. Frequency of occurrence of extratropical cyclone intensities as measured by (a) SLP (in $\mathrm{hPa}$ ), (b) relative vorticity at $850 \mathrm{hPa}\left(\right.$ in s$^{-1}$ ), and (c) wind speed at $925 \mathrm{hPa}\left(\right.$ in $\mathrm{m} \mathrm{s}^{-1}$ ) for ERA-Interim (yellow), T159 (solid black), T511 (solid red), T1279 (solid green), T2047 (solid blue), T15915min (dashed black), T511 (dashed red), and T511 $1_{\mathrm{O} 159}$ (dashed purple). With the exceptions of T511 and $\mathrm{T} 511_{\mathrm{O} 159}$, all intensities were computed using data at a resolution of T159. Results are based on winters (DJF) during the period 1989/90-2007/08. 

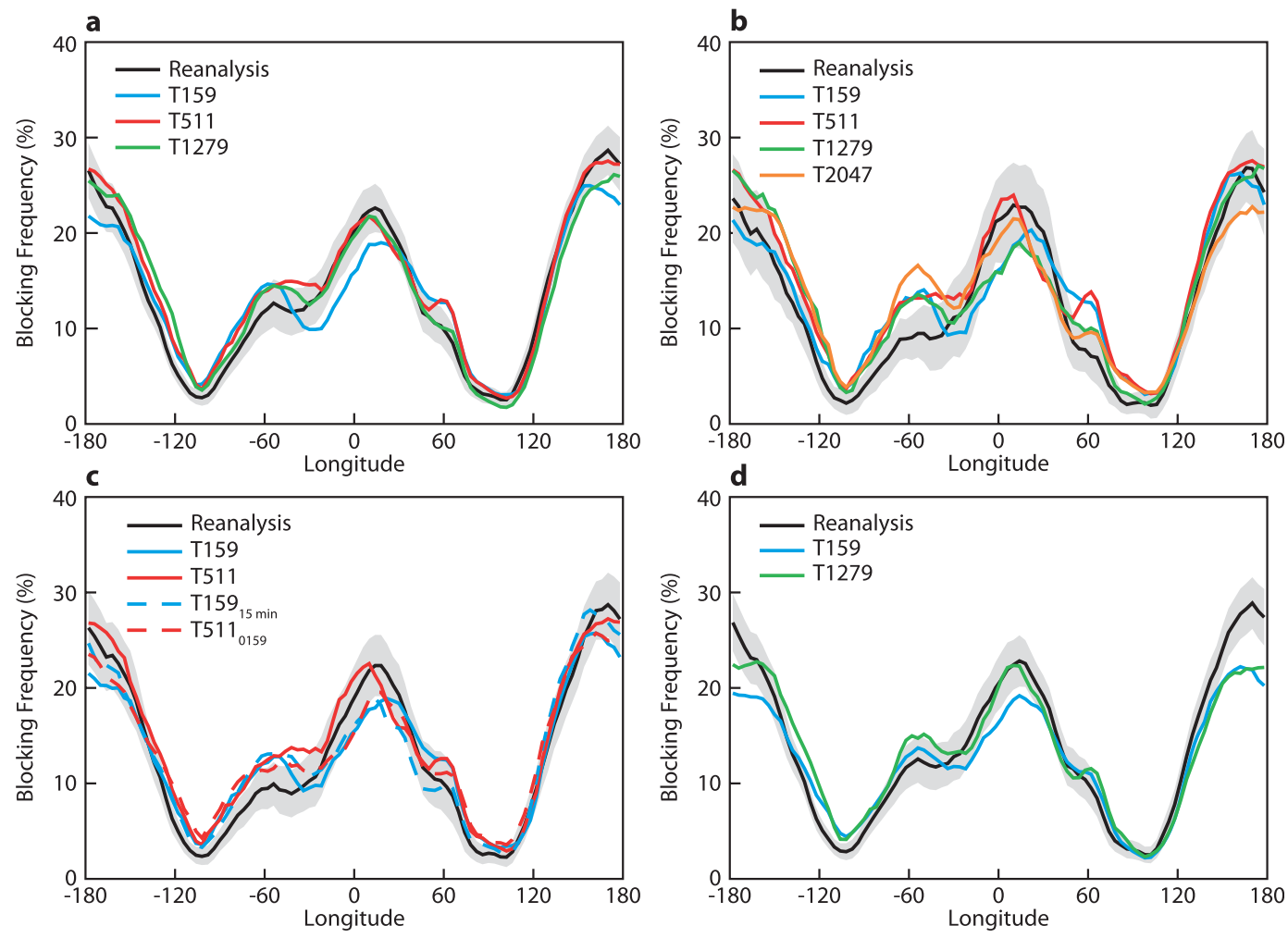

FIG. 8. Frequency of occurrence (in \%) of days at which the wintertime (December-March) Northern Hemisphere midlatitude flow is blocked: (a) ERA reanalysis (black with 95\% confidence level using a two-sided Student's $t$ test), T159 (blue), T511 (red), and T1279 (green) for the period 1960/61-2007/08. (b) As in (a), but for the shorter period 1989/90-2007/08 and with T2047 results (orange) included. Results in (a) and (b) are based on 13-month integrations. (c) As in (a), but for the period 1980/81-2007/08 and at T159 (blue), T511 (red), T159 ${ }_{15 \min }$ (dashed blue), and T511 0159 (dashed red). (d) As in (a), but for AMIP-style experiments and the shorter period 1962/63-2006/07.

extratropical cyclones over the Northern Hemisphere as a whole when going from T159 to T511 is not primarily due to a better resolved topography and hence a more realistic large-scale flow.

\section{2) Euro-ATLANTIC BLOCKING}

The frequency of occurrence of wintertime (DecemberMarch) blocking for the period 1960/61-2007/08 and 13-month integrations at T159, T511, and T1279 is shown in Fig. 8a. Results are based on the method outlined by Tibaldi and Molteni (1990). Two blocking maxima are clearly visible: one in the North Pacific and the other in the Euro-Atlantic region. In what follows, however, the focus will be on the Euro-Atlantic region for which the blocking procedure (i.e., the blocking latitude used) employed by Tibaldi and Molteni (1990) has been developed. Like other climate models (D'Andrea et al. 1998), the T159 version of the IFS underestimates EuroAtlantic blocking frequencies (see also Jung et al. 2010b). Increasing horizontal resolution to T511 (and further to T1279) completely eradicates this problem. The same diagnostics shown for the shorter period
1989/90-2007/08 and including the T2047 experiment (Fig. 8b) are more difficult to interpret due to the increased level of noise (larger confidence intervals and curves are more variable). This highlights the importance of using multidecadal integrations for assessing the ability of models to represent blocking statistics.

From the above discussion it becomes clear that the underestimation of the frequency of occurrence of EuroAtlantic blocking in the T159 version of the ECMWF model disappears when horizontal resolution is increased to T511. To get a better understanding of the possible causes of this improvement, wintertime blocking frequencies for the period 1980/81-2007/08 have been investigated in more detail, making use of the additional sensitivity experiments $\mathrm{T} 159_{15 \mathrm{~min}}$ and $\mathrm{T} 511_{\mathrm{O} 159}$ (Fig. 8c). Reducing the time step of the T159 model to $15 \mathrm{~min}$ has no discernible impact. If the T511 model is run with T159 orography, however, then Euro-Atlantic blocking frequencies drop back to values found for the T159 model. Similar results are obtained for systematic Z500 errors (not shown). In summary, these results show that it is necessary to have better resolved orography to get 


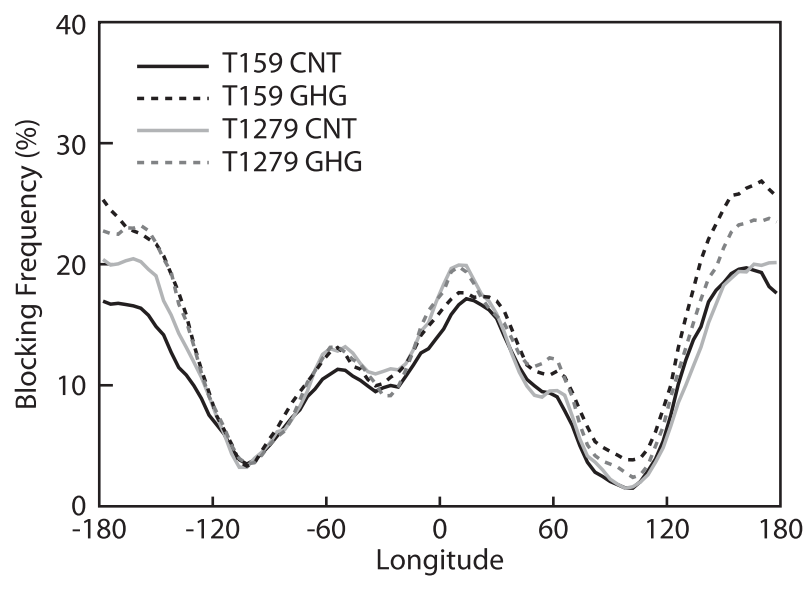

FIG. 9. Frequency of occurrence (in \%) of days at which the Northern Hemisphere midlatitude flow is blocked for winters (December-March): T159 for the periods 1962/63-2006/07 (black solid) and 2072/73-2116/17 (black dashed) and T1279 for the periods 1962/63-2006/07 (gray solid) and 2072/73-2116/17 (gray dashed).

the right blocking at T511. It is possible, however, that the high resolution also plays a role in getting better wave breaking, but this will not show up unless the orography is well resolved too.

The results presented so far were all based on 13-monthlong integrations, so it is worth investigating in more detail whether the same conclusions hold when the longer AMIP-type integrations are considered. Wintertime blocking frequencies for T159 and T1279 are shown in Fig. 8d for the period 1962/63-2006/07. Evidently, the conclusion that increasing resolution from T159 to T1279 improves blocking frequencies also holds in the AMIP-type experiments, at least over the eastern North Atlantic and Europe. This suggests that any possible slow drift of the soil properties beyond a few months (SST and sea ice are prescribed) does have only minor influences on the frequency of occurrence of EuroAtlantic blocking. In the North Pacific, on the other hand, AMIP-type integration shows larger blocking errors than shorter (1-4 month) integrations. Whether these differences result from difference in the dynamics of blocking between the North Pacific and the North Atlantic region and/or whether they are related to regional differences in how soil parameters drift in long integrations remains to be shown.

Given the sensitivity of Euro-Atlantic blocking characteristics to horizontal resolution described above, it is interesting to investigate whether the response of wintertime Euro-Atlantic blocking to anthropogenic forcing in the time-slice experiments is resolution dependent as well. Results for the time-slice experiments confirm that increasing the horizontal resolution from T159 to
T1279 increases Euro-Atlantic blocking frequencies. However, at both resolutions the response of Euro-Atlantic blocking frequencies to anthropogenic forcing is negligibly small (Fig. 9). In the North Pacific region, on the other hand, the response to anthropogenic forcing seems to be more strongly dependent on horizontal resolution.

\section{3) The Madden-Julian oscillation}

One might argue that the Madden-Julian oscillation (MJO) should be one of the atmospheric phenomena that should benefit most from increased horizontal resolution given the suspected importance of organized tropical convection. An MJO diagnostic, which is based on the average power spectra of tropical velocity potential anomalies at $200 \mathrm{hPa}$ [see Jung et al. (2005b) for details], is shown in Fig. 10 for reanalysis data and for the IFS at T159, T511, T1279, and T2047. The largest MJOtype variability is observed in the tropical Indian Ocean and over the Maritime Continent in the 40-60-day period band. At all resolutions tested here the IFS fails to produce the characteristic quasi-periodic variability in this period range. In fact, the simulated power spectra are effectively red at all four resolutions, especially in the Indian Ocean. This suggests that large-scale divergent wind anomalies in the tropical Indian Ocean are too persistent compared to the observations and that increasing horizontal resolution of the IFS from T159 to T2047 does not help to alleviate this problem. A more detailed investigation of the influence of horizontal resolution in the Athena experiments on the tropical intraseasonal oscillation will be reported upon in a forthcoming study (Achuthavarier et al., unpublished manuscript).

\section{Seasonal predictive skill}

In the following, the seasonal forecast ensembles will be analyzed to explore the role of increased horizontal resolution for seasonal forecast skill in the extratropics and tropics. The rationale for doing this is twofold. First, it could be argued that high resolution is required to simulate those processes better which are relevant for the atmospheric response to SST and sea ice anomalies. Second, a better mean model climate should lead to a more realistic response to SST and sea ice anomalies, both locally and remotely.

\section{a. Case study}

In the following, the winter of 2005/06 will be considered in more detail. This winter has been chosen because it was anomalously cold in northwest Europe due to an increased occurrence of Euro-Atlantic blocking (see Z500 anomalies in Fig. 11a), which was shown to be associated 


\section{a ERA}

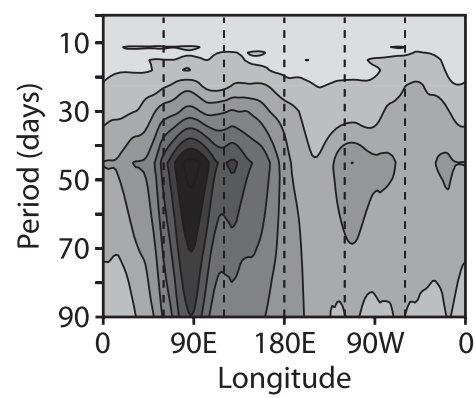

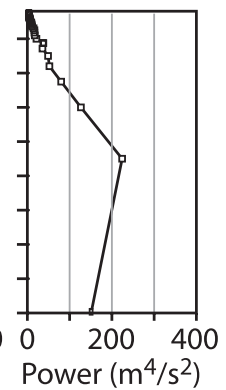

C $\mathrm{T} 511$
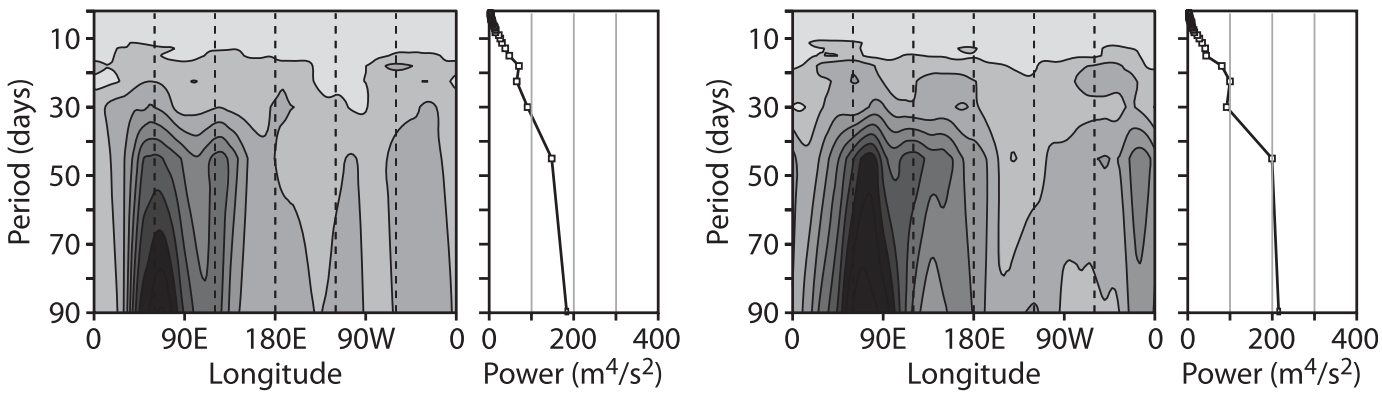

T2047

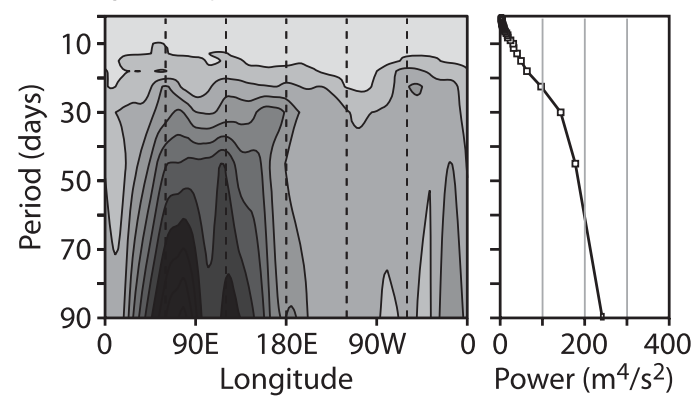

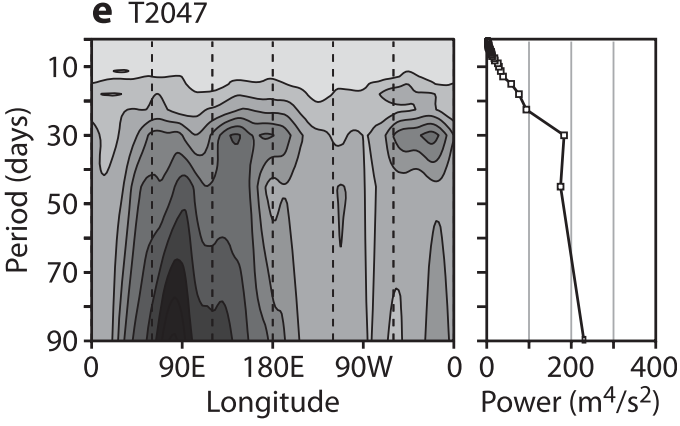

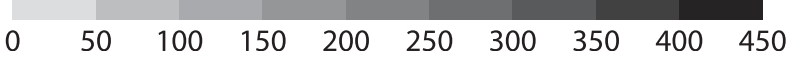

FIG. 10. Average power spectra $\left(\mathrm{m}^{4} \mathrm{~s}^{-2}\right)$ of tropical $\left(5^{\circ} \mathrm{S}-5^{\circ} \mathrm{N}\right)$ velocity potential anomalies for (a) ERA-40, (b) T159, (c) T511, (d) T1279, and (e) T2047. The average is based on 18 raw spectra obtained from each of the winter seasons (DJF) during the period 1989/90-2007/08. Model results are based on 13-month integrations. The mean annual cycle has been removed prior to the computation of the spectra. Zonal mean values are shown on the righthand sides of each of the panels.

with tropical circulation anomalies (Jung et al. 2010c). Although there is some reduction in the mean westerly wind in the North Atlantic region at T159 and especially at T1279, substantial differences between observed and ensemble mean Z500 anomalies remain (Fig. 11). While these discrepancies between observed and simulated anomalies may partly be due to the fact that the former is a single realization whereas the latter represents an ensemble mean (see Jung et al. 2010c), they also suggest that even at the highest of horizontal resolutions there is only modest seasonal forecast skill for this particular winter.

Visual inspection of similar maps for other winters confirms the conclusion that increasing horizontal resolution from T159 to T511 and T1279 has a relatively small impact (or none at all) on the skill of seasonal forecasts of atmospheric circulation anomalies over the Northern Hemisphere.

\section{b. Hindcast statistics}

In an attempt to allow for more quantitative statements to be made, probability density functions (PDFs) of anomaly correlation coefficients between individual seasonal forecasts (each season and ensemble member) and verifying reanalysis fields have been estimated. For seasonal forecasts of Northern Hemisphere Z500 anomalies the largest improvement in skill is found when going 
a ERA

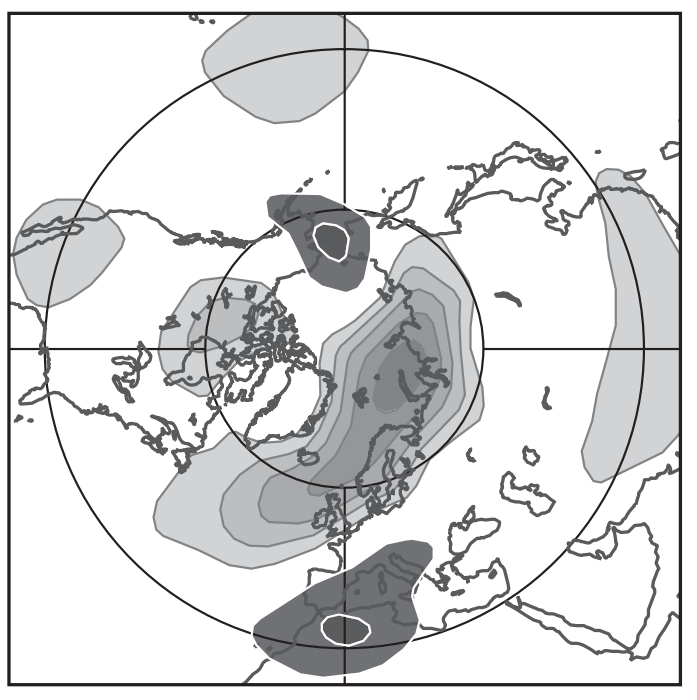

T511

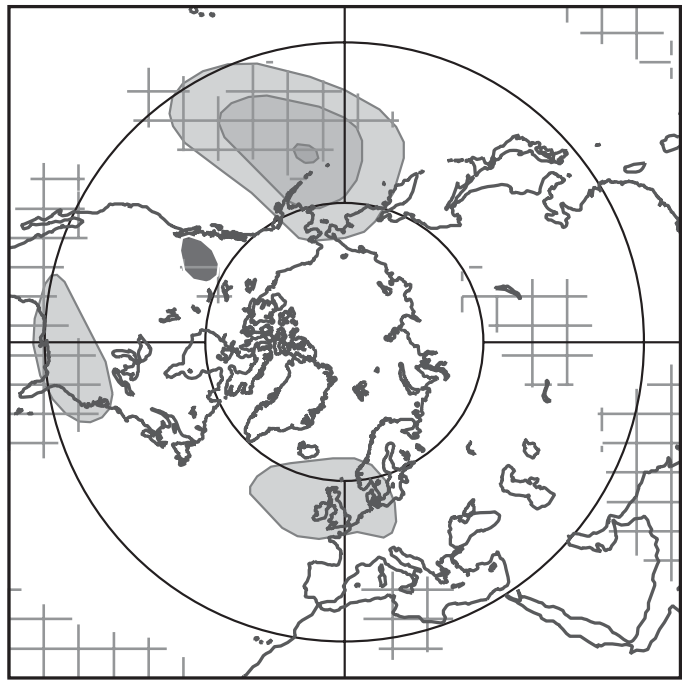

b $T 159$
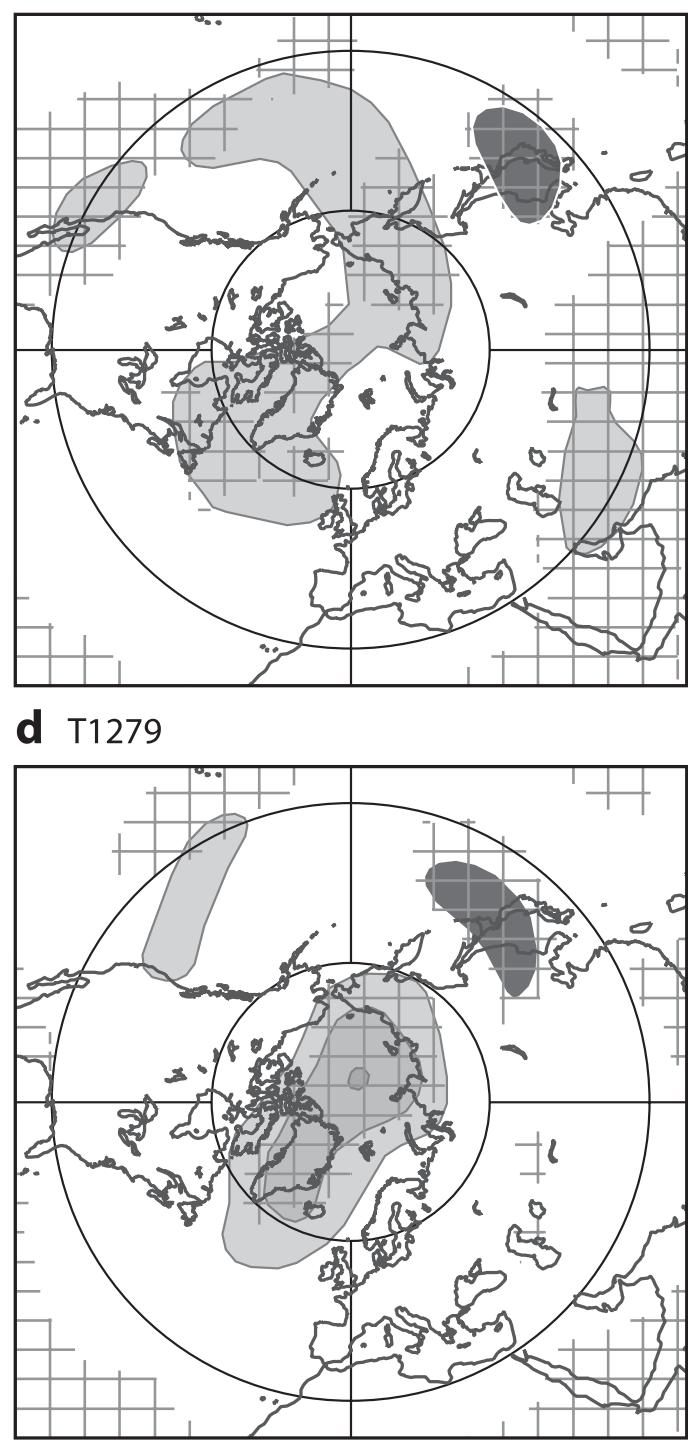

FIG. 11. Geopotential height anomalies at the 500-hPa level (contour interval is $25 \mathrm{~m}$ with lighter shading for positive anomalies) for the winter (DJF) of 2005/06 for (a) ERA-Interim and ensemble means of seasonal forecasts at (b) T159, (c) T511, and (d) T1279. Differences statistically significant at the 95\% confidence level are hatched.

from T511 to T1279 (Fig. 12a). The same is true for seasonal forecasts of tropical velocity potential anomalies at the 200-hPa level (Fig. 12b). This suggests that the use of the T1279 model leads to a better atmospheric response to tropical SST anomalies during boreal winter, which, through teleconnections, improves the seasonal forecast skill over the Northern Hemisphere extratropics.

For boreal summer no discernible impact of horizontal resolution on the skill of seasonal forecasts has been found, either in the tropics or in the Northern Hemisphere extratropics (not shown).

\section{Discussion}

In this study an extensive set of experiments carried out with the IFS in Project Athena is described and first results of the influence of horizontal resolution on model climate, selected atmospheric phenomena. and seasonal predictive skill are presented. Here, the focus is on relatively large-scale atmospheric features (synoptic and planetary) during boreal winter in the tropics and Northern Hemisphere extratropics. More detailed investigations of the hydrological diurnal cycle as well as atmospheric features across a range of different spatial scales will be 
a Northern Hemisphere Extratropics
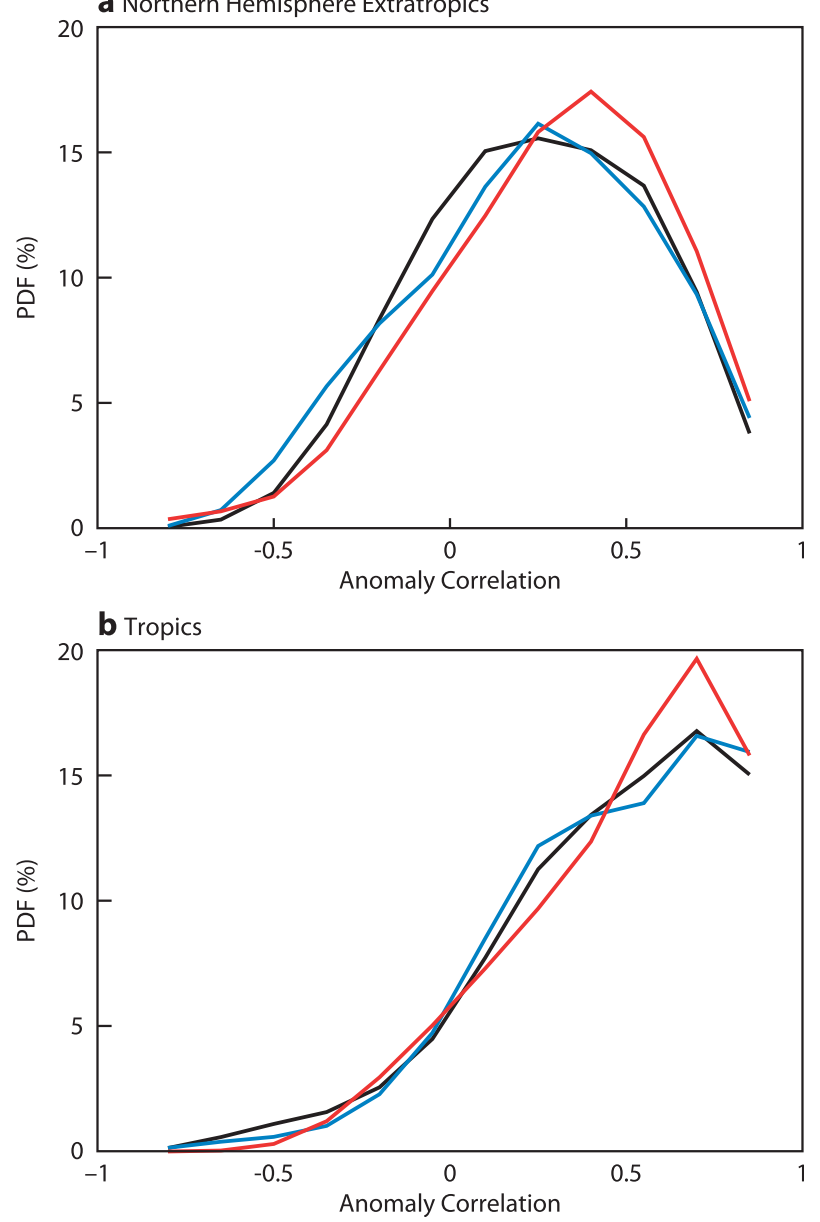

FIG. 12. Smoothed probability density functions (in \%) of anomaly correlation coefficients of wintertime (DJF) seasonal hindcasts at T159 (black solid), T511 (blue), and T1279 (red): (a) Northern Hemisphere (north of $30^{\circ} \mathrm{N}$ ) 500-hPa geopotential height and (b) tropical $\left(20^{\circ} \mathrm{S}-20^{\circ} \mathrm{N}\right)$ velocity potential anomalies at $200 \mathrm{hPa}$. Results are based on all single hindcasts from the period 1960/61$2007 / 08$ and the additional nine ensemble members for the winters of 1976/77, 1982/83, 1988/89, 1997/98, 1998/99, and 2005/06 (a total of 102 hindcasts). Smoothing was obtained by employing a Gaussian kernel scheme with a window width of $h=0.125$.

reported in companion papers (Kinter et al. 2011, manuscript submitted to Bull. Amer. Meteor. Soc.; Dirmeyer et al. 2012; Manganello et al. 2012; Satoh et al. 2012).

In general the influence of increased horizontal resolution in the extratropics on the mean atmospheric circulation of the IFS turns out to be relatively small. Perhaps this could have been anticipated, given that the lowresolution (T159) version of the IFS produces a quite realistic climatology (Jung et al. 2010a). However, it was found that increasing horizontal resolution improves the simulation of extratropical cyclone characteristics and the frequency of occurrence of Euro-Atlantic blocking events. This is consistent with previous studies (Jung et al. 2006; Matsueda et al. 2009). Interestingly, the largest improvement in Euro-Atlantic blocking is found when horizontal resolution is increased from T159 to T511; increasing resolution further to T1279 and T2047 has little if any impact. Additional sensitivity experiments reveal that the improvement in Euro-Atlantic blocking when going from T159 to T511 is associated with a better representation of the Earth's topography in the higherresolution model (see also Jung and Rhines 2007). When considering truncated fields (to T159), then it turns out that the largest improvement in extratropical cyclone characteristics is also obtained when going from T159 to T511. However, when it comes to mesoscale and subsynoptic aspects of extratropical cyclones, then increasing resolution beyond T511 leads to further modifications. Whether these changes are beneficial or not, however, is difficult to decide, given that reanalysis fields are not sufficiently well constrained by the observations on these relatively small spatial scales.

In the tropics increasing horizontal resolution is beneficial when it comes to simulating mean precipitation and the tropospheric circulation. As for the extratropics, it is found that the largest improvement in the tropics occurs when going from T159 to T511. A sensitivity experiment in which the T159 model was run with the time step of the T511 model reveals that the influence of reducing the time step (more smoothing and less active physics) on the tropical tropospheric circulation is comparable to, if not larger than, the pure effect of increased horizontal resolution.

The sensitivity of the MJO in the IFS to horizontal resolution turns out to be small, at least for the resolutions tested here. One possible explanation is based on the observation that the ratio of large-scale to convective tropical precipitation hardly changes with increasing resolution. This is in contrast, for example, to what has been found for the Community Atmospheric Model (Boyle and Klein 2010). While it is not clear how exactly this ratio should be changing with increasing resolution, it is worth noting that previous research has indicated that the strength and quasi periodicity of the MJO increases with an increasing ratio of large-scale to convective tropical rainfall (e.g., Tompkins and Jung 2004).

It is worth pointing out that there are certain aspects that become worse in the IFS with increasing resolution. One example is the quasi-biennial oscillation (QBO) whose period decreases unrealistically with increasing horizontal resolution (P. Bechtold 2010, personal communication). It is known that the period of the simulated QBO depends on the (parameterized and explicitly resolved) gravity wave activity (Giorgetta et al. 2002). This suggests that the deterioration of the simulated QBO 
period with increasing resolution could have been avoided or at least reduced had the model been tuned with the QBO in mind.

Seasonal forecasts carried out during Project Athena suggest that there might be some increase in predictive skill in the tropics and Northern Hemisphere extratropics during boreal winter when a resolution of T1279 is employed (compared to T159 and to T511). However, additional sensitivity experiments reveal that sampling uncertainty is an issue given the size of the signal compared to the sample size available. During boreal summer no discernible effect of horizontal resolution on seasonal predictive skill has been found. It is worth pointing out again that the seasonal forecast experiments were carried out with an atmosphere-only model. It is possible that the relative improvement in forecast skill with increased resolution would be larger for a coupled model given the reduction of the near-surface easterly wind bias and, therefore, the erroneous drift toward permanent La Niña conditions.

The additional sensitivity experiments (e.g., modified time step and orography) carried out on the ECMWF supercomputer after Project Athena had finished turned out to be very useful (see also Jung et al. 2010a) in improving our understanding of possible causes for the resolution dependence found in Project Athena. From this it is argued that additional resources for such experiments should be allocated to future projects to better understand the results and help draw meaningful conclusions.

The experiments carried out in Project Athena are relatively long multiseasonal-to-multidecadal integrations. This choice was made in order to investigate the impact of increased horizontal resolution on the climate of the model and its possible changes under global warming. It might be desirable, however, to augment such experiments by Transpose-AMIP type experiments, that is, by experiments in which atmospheric models are run and evaluated in numerical weather forecasting (NWP) mode (e.g., Phillips et al. 2004). In this way it would be possible to investigate in a computationally efficient way the impact of horizontal resolution on relatively fast and small-scale atmospheric processes such as deep convection, which are likely to be at the heart of many aspects of model uncertainty. Such an approach would also make it possible to use data from intensive observing periods for model diagnosis (e.g., Boyle et al. 2005) and therefore to further our understanding of the influence of horizontal resolution at the process level.

Project Athena shows that carrying out climate integrations (with the ECMWF model) with horizontal resolutions usually employed in NWP leads to relatively moderate improvements compared to low-resolution runs
(T159), at least for larger-scale aspects (synoptic and planetary scales) and diagnostics based on truncated fields. Improvements of similar size can also be found when deterministic physical parameterization schemes are changed (e.g., Jung et al. 2010a) and also when stochastic parameterization schemes are introduced (Jung et al. 2005a; Berner et al. 2008). This highlights the fact that increasing horizontal resolution is just one, albeit important, aspect of a concerted model development effort.

An interesting outcome of this study is the result that the largest changes are found when increasing horizontal resolution from T159 to T511 with relatively small further changes for T1279 and T2047. This raises the question as to whether there are certain "key resolutions" that are required in order to represent important aspects adequately. It is worth noting that the deterministic skill of ECMWF medium-range forecasts improved dramatically when the T511 model was introduced in the autumn of 2000 (Simmons and Hollingsworth 2002); on the other hand, subsequent further resolution increases to T799 and T1279 led to relatively smaller improvements. It is also possible, of course, that the relatively small impact found in this study when going to T1279 and T2047 is due to a lack of tuning. In fact, prior to the start of Project Athena there was very limited experience at ECMWF with the T1279 model and virtually none with T2047, even in NWP applications. Finally, one should not discard the possibility that T1279 and T2047 are approaching a gray zone of horizontal resolutions where the validity of the assumptions underlying the design of the existing IFS model fundamentally weaken. Therefore, one conclusion that may be drawn from the relatively small impact found for the diagnostics presented in this study is the need for a careful review of the impact and the validity of assumptions such as columnar physics, cloud microphysics versus convection parameterization, hydrostaticity, and the lack of explicit horizontal turbulence. Hence, despite using state-of-the-art numerical models, this study cannot ultimately answer the question if simulations at horizontal resolutions $O(1 \mathrm{~km})$ that necessitate fundamental model changes in the aforementioned areas would not lead to fundamental breakthroughs in the simulation of weather and climate.

Acknowledgments. The results described herein were obtained during the 2009-10 Athena Project, a computationally intensive project that was carried out using the Athena supercomputer at the University of Tennessee's National Institute for Computational Sciences (NICS), under the auspices of the National Science Foundation (NSF). Support provided by NICS and the NSF are gratefully acknowledged. The following individuals contributed to the project: P. Bechtold, A. Beljaars, 
M. Rodwell, M. Fuentes, R. Correa, A. Brady, and C. Valiente from ECMWF; P. Andrews, T. Baer, M. Ezell, C. Halloy, D. John, B. Loftis, and K. Wong from NICS; P. Dirmeyer, B. Doty, B. Huang, J. Manganello, D. Strauss, T. Wakefield from COLA; and E. Jin from George Mason University. Anabel Bowen improved the quality of the figures. Comments by three anonymous reviewers helped clarify the paper.

\section{REFERENCES}

Adler, R. F., and Coauthors, 2003: The version-2 Global Precipitation Climatology Project (GPCP) monthly precipitation analysis (1979-present). J. Hydrometeor., 4, 1147-1167.

Balsamo, G., P. Viterbo, A. Beljaars, B. van der Hurk, M. Hirschi, A. K. Betts, and L. Scipal, 2009: A revised hydrology for the ECMWF model: Verification from field site to terrestria water storage and impact in the integrated forecast system. J. Hydrometeor., 10, 623-643.

Bechtold, P., M. Köhler, T. Jung, F. Doblas-Reyes, M. Leutbecher, M. Rodwell, F. Vitart, and G. Balsamo, 2008: Advances in simulating atmospheric variability with the ECMWF model: From synoptic to decadal time scales. Quart. J. Roy. Meteor. Soc., 134, 1337-1351.

Beljaars, A. C. M., 1995: The impact of some aspects of the boundary layer scheme in the ECMWF model. Proc. Seminar on Parameterization of Subgrid Physical Processes, Reading, United Kingdom, ECMWF, 125-161.

_ , P. Bechtold, M. Köhler, J.-J. Morcrette, A. M. Tompkins, P. Viterbo, and N. Wedi, 2004: The numerics of physical parameterization. Proc. Seminar on Recent Developments in Numerical Methods for Atmospheric and Ocean Modelling, Reading, United Kingdom, ECMWF, 113-134.

Bengtsson, L., K. Hodges, and E. Roeckner, 2006: Storm tracks and climate change. J. Climate, 19, 3518-3543.

,-- , and N. Keenlyside, 2009: Will extratropical storms intensify in a warmer climate? J. Climate, 22, 2276-2301.

Berner, J., F. Doblas-Reyes, T. Palmer, G. Shutts, and A. Weisheimer, 2008: Impact of a quasi-stochastic cellular automaton backscatter scheme on the systematic error and seasonal prediction skill of a global climate model. Philos. Trans. Roy. Soc. London, 366A, 2561-2579.

Boyle, J., and S. Klein, 2010: Impact of horizontal resolution on climate model forecasts of tropical precipitation and diabatic heating for the twp-ice period. J. Geophys. Res., 115, D23113, doi:10.1029/2010JD014262.

_ and Coauthors, 2005: Diagnosis of Community Atmospheric Model 2 (CAM2) in numerical weather forecast configuration at Atmospheric Radiation Measurement sites. J. Geophys. Res., 110, D15S15, doi:10.1029/2004JD005042.

Branković, C., and D. Gregory, 2001: Impacts of horizontal resolution on seasonal integrations. Climate Dyn., 18, 123-143.

Brown, A. R., 2004: Resolution dependence of orographic torques. Quart. J. Roy. Meteor. Soc., 130, 3029-3046.

Collins, W., and Coauthors, 2006: The Community Climate System Model version 3 (CCSM3). J. Climate, 19, 2122-2143.

D'Andrea, F., and Coauthors, 1998: Northern Hemisphere atmospheric blocking as simulated by 15 atmospheric general circulation models in the period 1979-1988. Climate Dyn., 14, 385-407.

Dirmeyer, P., and Coauthors, 2012: Simulating the hydrological diurnal cycle in global climate models: Resolution versus parametrization. Climate Dyn., in press.
Gates, W. L., 1992: AMIP: The Atmospheric Model Intercomparison Project. Bull. Amer. Meteor. Soc., 73, 1962-1970.

Giorgetta, M., E. Manzini, and E. Roeckner, 2002: Forcing of the quasi-biennial oscillation from a broad spectrum of atmospheric waves. Geophys. Res. Lett., 29, 1245, doi:10.1029/2002GL014756.

Hodges, K., 1995: Feature tracking on the unit sphere. Mon. Wea. Rev., 123, 3458-3465.

1996: Spherical nonparametric estimators applied to the UGAMP model integration for AMIP. Mon. Wea. Rev., 124, 2914-2932

, 1999: Adaptive constraints for feature tracking. Mon. Wea. Rev., 127, 1362-1373.

- 2008: Confidence intervals and significance tests for spherical data derived from feature tracking. Mon. Wea. Rev., 136, 1758-1777.

-, R. Lee, and L. Bengtsson, 2011: A comparison of extratropical cyclones in recent reanalyses: ERA-INTERIM, NASA-MERRA, NCEP-CFSR and JRA25. J. Climate, 24, 4888-4906.

Hortal, M., and A. Simmons, 1991: Use of reduced Gaussian grids in spectral models. Mon. Wea. Rev., 119, 1057-1074.

Hoskins, B. J., and K. I. Hodges, 2002: New perspectives on the Northern Hemisphere winter storm tracks. J. Atmos. Sci., 59, 1041-1061.

Jung, T., 2005: Systematic errors of the atmospheric circulation in the ECMWF forecasting system. Quart. J. Roy. Meteor. Soc., 131, 1045-1073.

and P. B. Rhines, 2007: Greenland's pressure drag and the Atlantic storm track. J. Atmos. Sci., 64, 4004-4030.

- T. N. Palmer, and G. J. Shutts, 2005a: Influence of a stochastic parameterization on the frequency of occurrence of North Pacific weather regimes in the ECMWF model. Geophys. Res. Lett., 32, L23811, doi:10.1029/2005GL024248.

- A. M. Tompkins, and M. J. Rodwell, 2005b: Some aspects of systematic error in the ECMWF model. Atmos. Sci. Lett., 6, 133-139.

- S. K. Gulev, I. Rudeva, and V. Soloviov, 2006: Sensitivity of extratropical cyclone characteristics to horizontal resolution in the ECMWF model. Quart. J. Roy. Meteor. Soc., 132, 18391857.

and Coauthors, 2010a: The ECMWF model climate: Recent progress through improved physical parametrizations. Quart. J. Roy. Meteor. Soc., 136, 1145-1160.

— M. Miller, and T. Palmer, 2010b: Diagnosing the origin of extended-range forecast error. Mon. Wea. Rev., 138, 24342446.

—, T. N. Palmer, M. J. Rodwell, and S. Serrar, 2010c: Understanding the anomalously cold European winter of 2005/06 using relaxation experiments. Mon. Wea. Rev., 138, 3157-3174.

Manganello, J., and Coauthors, 2012: Tropical cyclone climatology in a $10-\mathrm{km}$ global atmospheric GCM: Toward weatherresolving climate modeling. J. Climate, in press.

Matsueda, M., R. Mizuta, and S. Kusunoki, 2009: Future change in wintertime atmospheric blocking simulated using a $20-\mathrm{km}$ mesh atmospheric global circulation model. J. Geophys. Res., 114, D12114, doi:10.1029/2009JD011919.

Morcrette, J.-J., H. W. Barker, J. N. S. Cole, M. J. Cole, M. J. Iacono, and R. Pincus, 2008: Impact of a new radiation package, McRad, in the ECMWF Integrated Forecasting System. Mon. Wea. Rev., 136, 4773-4798.

Phillips, T. J., and Coauthors, 2004: Evaluating parameterizations in general circulation models: Climate simulation meets weather prediction. Bull. Amer. Meteor. Soc., 85, 1903-1915. 
Rayner, N. A., D. E. Parker, E. B. Horton, C. K. Folland, L. V. Alexander, D. P. Rowell, E. C. Kent, and A. Kaplan, 2003: Global analyses of sea surface temperature, sea ice, and night marine air temperature since the late nineteenth century. J. Geophys. Res., 108, 4407, doi:10.1029/2002JD002670.

Reynolds, R., N. Rayner, T. Smith, M. Thomas, D. Stokes, and W. Wang, 2002: An improved in situ satellite SST analysis for climate. J. Climate, 15, 73-87.

Ritchie, H., C. Temperton, A. Simmons, M. Hortal, T. Davies, D. Dent, and M. Hamrud, 1995: Implementation of the semiLagrangian method in a high-resolution version of the ECMWF forecast model. Mon. Wea. Rev., 123, 489-514.

Satoh, M., and Coauthors, 2012: The intra-seasonal oscillation and its control of tropical cyclones simulated by high-resolution global atmospheric models. Climate Dyn., doi:10.1007/s00382011-1235-6, in press.

Schneider, E. K., M. J. Fennessy, and J. Kinter III, 2009: A statisticaldynamical estimate of winter ENSO teleconnections in a future climate. J. Climate, 22, 6624-6638.

Shukla, J., R. Hagedorn, M. Miller, T. N. Palmer, B. Hoskins, J. Kinter, J. Marotzke, and J. Slingo, 2009: Revolution in climate prediction is both necessary and possible: A declaration at the World Modeling Summit for Climate Prediction. Bull. Amer. Meteor. Soc., 90, 16-19.

Simmons, A. J., and A. Hollingsworth, 2002: Some aspects of the improvement of skill of numerical weather prediction. Quart. J. Roy. Meteor. Soc., 128, 647-677.

— S. Uppala, D. Dee, and S. Kobayashi, 2007: ERA-Interim: New ECMWF reanalysis products from 1989 onwards. ECMWF Newsletter 110, ECMWF, Reading, United Kingdom, 25-35.
Temperton, C., M. Hortal, and A. Simmons, 2001: A two-timelevel semi-Lagrangian global spectral model. Quart. J. Roy. Meteor. Soc., 127, 111-127.

Tibaldi, S., and F. Molteni, 1990: On the operational predictability of blocking. Tellus, 42A, 343-365.

Tiedtke, M., 1989: A comprehensive mass flux scheme for cumulus parameterization in large-scale models. Mon. Wea. Rev., 117, 1779-1800.

_ 1993: Representation of clouds in large-scale models. Mon. Wea. Rev., 121, 3040-3061.

Tompkins, A. M., and T. Jung, 2004: Influence of process interactions on MJO-like convective structures in the IFS model. ECMWF/CLIVAR Workshop on Simulation and Prediction of Intra-Seasonal Variability with Emphasis on the $M J O$, ECMWF, Reading, United Kingdom, 103-114.

Untch, A., and M. Hortal, 2004: A finite-element scheme for the vertical discretization of the semi-Lagrangian version of the ECMWF model. Quart. J. Roy. Meteor. Soc., 130, 1505-1530.

Uppala, S., and Coauthors, 2005: The ERA-40 Re-Analysis. Quart. J. Roy. Meteor. Soc., 131, 2961-3012.

Viterbo, P., and A. C. M. Beljaars, 2005: An improved land surface parameterization scheme in the ECMWF model and its validation. J. Climate, 8, 2716-2748.

Williamson, D. L., J. T. Kiehl, and J. J. Hack, 1995: Climate sensitivity of the NCAR Community Climate Model (CCM2) to horizontal resolution. Climate Dyn., 11, 377-397.

Woollings, T., B. J. Hoskins, M. Blackburn, D. Hassel, and K. I. Hodges, 2010: Storm track sensitivity to sea surface temperature resolution in a regional atmosphere model. Climate Dyn., 35, 341-353. 